\title{
LA INTERPRETACIÓN RUSSELLIANA DE LEIBNIZ Y EL ATOMISMO METODOLÓGICO DE MOORE
}

\author{
FranCisco Rodrf́GUEz CONSUEGRA \\ MCMASTER UNIVERSITY, HAMILTON \\ INSTTtuto S. Vilaseca, ReUs
}

El objetivo concreto de este trabajo es mostrar el carácter sistemático y metodológico de la influencia de Moore sobre el joven Russell, cosa que estaba por hacer. Ello se intenta básicamente en el núcleo central del artículo (secs. 2-10) que está precedido por una introducción sobre la etapa "hegeliana" (sec. 1) y seguido, a título de conclusión, por un breve estudio de ese manifiesto del Russell mooreano que fue su trabajo ante el Congreso de París de 1900 (sec. 11). 1

\section{La "fase hegeliana"}

Tanto en 1959a como en 1967a Russell ha hablado de una fase hegeliana en la cual trató de llevar a cabo con la física lo mismo que en 1897a había hecho con la geometría. Tal fase, situada (más o menos) entre 1896 y 1898 no dio lugar a más publicación importante que $1897 \mathrm{c},{ }^{2}$ al que me referiré más adelante, aunque produjo una cierta cantidad de material manuscrito. No estudiaré aquí

1 Este artículo se enmarca en el contexto de otros trabajos míos sobre el entorno filosófico del joven Russell. En particular, pretende complementar escritos previos sobre la influencia de Moore en los manuscritos inéditos russellianos de 1898-1900 (mis 1898a y 1991, cap. 2), en el sentido de que sólo en la obra sobre Leibniz y en el trabajo presentado ante el Congreso de Paris en 1900 tal influencia aparece en toda su importancia. Sobre ta primera filosofía de Moore, véase mi 1990e

2 Hay también dos recensiones más o menos relevantes, pero que aportan muy poco sobre el propio pensamiento de Russell. La primera es 1898a y trata de una obra de física teórica (véase la bibliografía). Lo único destacable en ella para nosouros es el fuerte rechazo de Mach y Pearson, cuya tendencia se califica de "dogmatismo antimetafísico" (p. 405), y el entusiasmo con que se apoya el intento del autor de construir una teoría de la mecánica abstracta y puramente lógica (p. 406). La segunda es 1899a, donde se alaban los cuidadosos análisis de una obra de Meinong (p. 251) y se aportan comentarios muy generales e indecisos sobre el tema de la cantidad (que estaba forjando entonces en los manuscritos). 
todo ese material; primero porque ese trabajo ha sido ya realizado ${ }^{3}$ y segundo porque su interés para nuestro objetivo general es escaso y afecta sólo a unos pocos fragmentos sobre la definición, la presuposición y el esquema general hegeliano, que ya estaban presentes en buena medida en 1897a y en m 1898 (como he mostrado en mis 1990a y 1988a y 1991a).

En esta fase la aplicación de las ideas de Hegel se concreta en la pretención de constituir una "dialéctica (o lógica) de las ciencias" que, permitiendo cierta contradicción, inevitable dado el carácter existencial (sensorial) de sus objetos, vaya elevándose a niveles superiores donde las contradicciones (evitables) queden superadas. Ello exigiría, según Russell, que cada ciencia quedara reducida a unos pocos "postulados" (1959a, 40), cuyo ordenamiento posibilitaría un mínimo de contradicción, los cuales constituirían la base de la transición a ciencias superiores, más abarcantes. Tales ciencias deberán mostrar lo incompleto y "abstracto" de las inferiores y cómo tales insuficiencias conducen, inevitablemente, a contradicciones. Este sería el fundamento teórico.

En lo efectivamente realizado por Russell (lo mejor de lo cual fue al menos publicado en 1959a) encontramos, en cambio, argumentos más o menos convencionales. Como se ve, por ejemplo, en su preferencia por la teoría de la materia como un plenum, tradicionalmente opuesta a la teoría atomística. Spadoni (1977a, 153-4) ha visto en esa elección una consecuencia del monismo hegeliano. Pero el juicio del propio Russell con la perspectiva de los años la justifica aduciendo, simplemente, que la teoría de Maxwell ${ }^{4}$ acababa con la acción a distancia y poseía, además, argumentos empíricos a su favor: "Cuando adopté el punto de vista más moderno, le puse un ropaje hegeliano y lo representé como una transición dialéctica de Leibniz a Spinoza, permitiéndome así aceptar el predominio del orden lógico sobre la cronología” (1959a, 33). Por consiguiente la práctica metodológica aceptaba sólo el lenguaje hegeliano, guiándose, en lo demás, por otras consideraciones.

Por eso su práctica de la definición como método habitual no se ve trastornada por el hegelianismo, que permite que Russell vaya "probando" las consecuencias de las diversas definiciones de "materia" para el conjunto de la física, teniendo en cuenta los criterios habituales de coherencia, realismo y economía. Así, cuando aún no disponía de una teoría de la definición ni tampoco de la posibilidad teórica de admitir "simples", comenzaba, no obstante, a considerar la importancia de las construcciones para la ordenación de aquellos postulados mínimos que mencionaba más arriba. (De hecho, la distinción

3 Primero por Spadoni 1977a, que ofrece en su tesis una buena base (de la que a veces me he servido con provecho) para estudiar esta etapa de Russell, $;$ más reciente y exhaustivamente por Griffin 1988a y 1990a.

4 No hay que olvidar que Whitehead había hecho la tesis sobre Maxwell y como Russell confiesa, lo incitó hacia esa teoría (1959a, 33). Otra muestra de lo decisivo de la influencia de su antiguo profesor (a añadir a la que ya es visible en los manuscritos). 
entre conceptos y axiomas no estaba ni siquiera clara en los manuscritos de la época).

Es cierto que su teoría actual de la construcción no rebasaba el marco bradleiniano y, por tanto, se veía incapacitada para establecer jerarquías claramente ontológicas, pero, al menos, tal teoría hacía posible la formulación de definiciones como intentos de "ordenar" un conjunto de conceptos a la búsqueda de la máxima coherencia compatible con la inevitabilidad de las contradicciones. Sin embargo el método bradleiniano, aunque facilitaba la formulación de diversas construcciones (al ser "abstracciones", ninguna podía ser del todo verdadera), no tomaba las precauciones necesarias con el manejo del lenguaje ordinario y corría el peligro de aceptar lo que sólo eran ideas más o menos intuitivas. Faltaba el nexo entre la intuición y los indefinibles para dar un sentido más realista a las construcciones. Sin él, no era fácil elegir entre posibilidades lógicamente aceptables, como lo muestra esta reseña: ${ }^{5}$

Tres construcciones teóricas se expusieron, cada una conduciendo dialécticamente a la otra, primeramente el átomo científico en un espacio real -en segundo lugar el espacio como naturaleza última de la materia - finalmente la materia concebida de manera idealista como una mónada física. El método dialécrico fue claramente seguido.

Un indicio más a favor de la interpretación de tales transiciones dialécticas como un mero ropaje hegeliano está en el hecho de que las construcciones teóricas se presentaban como un intento de superar el dualismo entre apariencia y realidad, por lo que estaba latente ya la auténtica consideración de la "construcción" como forma de dar cuenta de la apariencia. En un fragmento de la época leemos acerca de la necesidad de "encontrar un método para convertir la Apariencia en Realidad en lugar de construir primero la Realidad y enfrentarnos entonces a un dualismo sin esperanza" (1959a, 34). No estoy sugiriendo con ello que la rebelión de Russell contra Hegel fuese de tipo empirista (uno de los mitos que deshace Spadoni 1977a); su teoría lógica del juicio se lo impedía al exigirle la visión de los conceptos como contenidos lógicos y no como realidades basadas en lo meramente "existente". Pero, en todo caso, es indudable que el dualismo se presentaba como una dificultad a la hora de ordenar esos postulados mínimos que habían de dar cuenta de cada ciencia.

La teoría relacional del juicio de Moore vendría, poco más tarde, a solventar esta pega borrando la distinción sujeto-predicado y, con ella, la de sustanciaatributo. Pero, ya en diciembre de 1897 aboga Russell por la eliminación del dualismo entre apariencia y realidad anticipándose así (por lo que parece) al

5 Citada por Clark 1975a, p. 84. El texto reseñado procede de un ensayo perdido de Russell titulado "The Constitution of Matter" que fue leido en febrero de 1898. 
propio Moore. Se trata de $1897 f$, donde se califica la distinción aparienciarealidad de dualismo inútil, sobre la base de que toda nuestra experiencia se halla unida al tiempo, que nos impide hablar de una auténtica Realidad, y se concluye: "la Realidad, tal como la construye la metafísica, no mantiene ningún tipo de relación con el mundo de la experiencia. Es una abstracción vacía de la que no puede efectuarse de forma válida ni una simple inferencia con respecto al mundo de la apariencia"( $1897 \mathrm{f}, 108)$. Por tanto, aunque no podamos ciertamente hacer del Russell posthegeliano un empirista, al menos sí que podemos atribuirle una preocupación metodológica en torno a la necesidad de establecer un nexo entre las construcciones, por muy abstractas que sean, y la apariencia.

En todo caso es indudable que incluso en esta supuesta fase hegeliana Russell continuó pensando, como en 1897a, que es imprescindible reducir las ciencias a aquellas ideas básicas que, estando presupuestas en sus desarrollos, permiten dar cuenta, después, de esos mismos contenidos. Lo distintivo de esta fase radicaría precisamente en el intento de entrever la posibilidad de constituir una "lógica" de todas las ciencias. Y ello, separando el ropaje hegeliano, no es sino aquel "logicismo" sui generis de los manuscritos de 1898-1900 y plenamente desarrollado en 1903a. En el siguiente fragmento esta idea se halla claramente expresada (1959a, 40):

Toda ciencia trabaja con un cierto número limitado de ideas fundamentales cuyo número es inferior al de la totalidad de las ideas fundamentales. Entonces toda ciencia puede considerarse como un intento de construir un universo a partir de sus propias ideas. Por tanto, lo que hemos de hacer en un lógica de las ciencias es constituir, con el conjunto apropiado de ideas, un mundo que no contenga más contradicciones que aquellas que sean inevitables dado lo incompleto de esas ideas.

Y ello sin olvidar que, en última instancia, el modelo de contradicción típica es, y seguirá siendo, para Russell, la "contradicción de la relatividad" que, como veremos más abajo, en la práctica trató de resolver por medios convencionales, sin hacer demasiado uso de los recursos típicos hegelianos.

En cualquier caso el fragmento citado es válido, con las adaptaciones lingüísticas relevantes, para el método que persistió en toda la obra russelliana. Muestra cómo la idea de construcción viene de Bradley y nos da la base para apreciar la forma en que, con las aportaciones de Moore (la definición y el análisis en indefinibles), Russell adquiriría un nuevo modo de construir, pero siempre pensando en dar cuenta del contenido de las ciencias. Y ello a pesar de que la influencia mooreana incluyera un nuevo respeto por el lenguaje ordinario extrañamente incompatible con el esencialismo del "verdadero significado". El hecho de que los manuscritos articulen una teoría de la presuposición y un método explícito de definición, no hace más que mostrar la unidad 
metodológica subyacente y pone un tanto en duda la profundidad de la "fase" hegeliana.

Por todo ello, si vemos los indefinibles desde una óptica amplia que incluya los indemostrables, parece obvio que constituyen una constante en toda la obra russelliana. Además, es visible aquí también otra característica que estará igualmente presente en toda su obra: la de construir "teorías" posibles partiendo de ciertas definiciones sencillas, evitando la contradicción y procurando dar cuenta del significado ordinario de los términos utilizados. El que después Russell evolucionara hacia una postura más linguiística, en el sentido de que las nuevas construcciones establecerian significados más que limitarse a constatarlos (lo que supondría ya un avance hacia el lenguaje ideal) no impide que consideremos el método de las construcciones como algo, en sí mismo, constante.

Como he explicado en mi 1988a, buena parte de las dificultades para admitir a Cantor 6 estaban precisamente en que sus construcciones romplan con la intuitividad del lenguaje ordinario. Pero esa línea de pérdida de la intuitividad no rompe, en modo alguno, con el esencialismo. Lejos de ello, permite seguir manteniendo la existencia de significados verdaderos, bien referidos a los sentidos habituales de las palabras (Moore), bien procedentes de la construcción misma (la "libertad" del matemático para "crear" objetos según Dedekind y Cantor). Como veremos en un momento, 1903a fue el terreno en que tuvo lugar esa batalla.

Terminaré la sección con algunas referencias a 1897 c, climax de esta supuesta fase hegeliana, con objeto de reforzar la tesis según la cual Hegel fue sólo un ropaje que, por debajo, ejemplifica la continuidad existente entre 1897a, los manuscritos de 1898-1900 y 1903a. Desde el punto de vista del contenido, se trata de la primera publicación donde Russell aborda directamente la relación entre el número y la cantidad (quantity), ${ }^{7}$, muy influido por la postura de Couturat 1896a, la recensión que escribió del cual tocaba ya el tema y situaba las opciones posibles, sin tomar aún partido.

1897 c comienza subrayando la importancia filosófica del problema advirtiendo que será tratado desde una visión específicamente lógica, destinada sobre todo a clarificar el significado de lo "continuo". Pronto pasa Russell a plantear el problema principal: la relación entre la cantidad y el número.

6 Russell leyó 1894 a de Hertz en febrero de 1898 (según consta en 1902f). Su lectura debió contribuir, por un lado, a su idea de reducir las ciencias a unos pocos conceptos o ideas (Hertz redujo allí la mecánica a tres conceptos y un axioma). Pero, por otro lado, el neokantismo de Hertz, que consideraba tales conceptos como dados a priori, pudo también contribuir a atar a Russell a una postura contraria a esa pérdida de la intuitividad que caracterizaba, por ejemplo, las construcciones de Cantor.

7 Aquí Russell todavía considera la "cantidad" como lo general y la "magnitud" como lo particular (el resultado de una medida); lo cual cambió después. 
Para que el número, aplicado a lo continuo, nos proporcione información real sobre la materia medida es necesario que ésta se halle de por sí dividida en unidades, a riesgo de basarnos en algo puramente convencional y arbitrario. Es decir, es necesario que la cantidad sea previa al número para que, después, llevemos a cabo la medida mediante la comparación con la unidad (otra cantidad). Esto equivale a decir que la cantidad debe ser una propiedad intrínseca de nuestra unidad de medida y no el resultado de una comparación, lo que crea una "antinomia".

Russell propone dos vías de salida; o la cantidad es una categoría independiente o un dato inmediato de los sentidos. De acuerdo con la primera salida (la de Couturat) se ha de distinguir entre cantidades extensivas e intensivas. Tratándose de las primeras, se llega también a una antinomia: la cantidad extensiva es un atributo, pues es homogénea con el cambio (que lo es), pero también es algo más (una "sustancia"), ya que puede dividirse en partes (es "sujeto" del cambio). ${ }^{8}$ Russell concluye que el problema cesa cuando dejamos de ver las cantidades como relaciones hipostasiadas, es decir, cuando dejamos de considerarlas divisibles. Con ello exhibe su plena dependencia de Bradley, impenitente negador de toda posibilidad de admitir "simples", y que tanto gustaba de conducir cualquier intento de establecerlos a un resultado contradictorio.

Considerando ahora la segunda salida, dice Russell que las cantidades intensivas son aquellas cuyas diferencias no son también cantidades, por lo que hacen imposible la medición numérica. También éstas conducen a la antinomia; por un lado su posible diferencia sería sólo el resultado de la comparación y, por ello, una relación; por otro, para que la comparación sea posible hemos de partir ya de una cantidad, que no es en sí misma una relación. Como las dos salidas llevan a contradicción, la cantidad no puede verse como categoría independiente.

Pero tampoco admite Russell que la cantidad sea un dato de los sentidos. Se apoya, para ello, en un trabajo anterior de Poincaré: si la cantidad fuese un dato de los sentidos, sensaciones indiscernibles darían lugar a cantidades iguales (distinguiríamos, por ejemplo, $\mathrm{A}$ de $\mathrm{C}$, aunque no $\mathrm{A}$ de $\mathrm{B}$ ni $\mathrm{B}$ de $\mathrm{C}$ ). Por tanto la cantidad no es sensorial.

La fuente de error está, según Russell, en suponer que la cantidad es una propiedad común obtenible por abstracción: la cantidad "no es una propiedad común de las cosas cuantitativas más que la similaridad pueda serlo de las cosas similares" (1897c, 337). Muy al contrario, expresa sólo la posibilidad de cierta comparación entre "contenidos". Por lo que es absurdo buscar la naturaleza de la cantidad analizando cantidades particulares, como lo sería hacer lo propio con el parecido (likeness) estudiando fotografias. La cantidad

8 Sigo aquí la útil terminología de Couturat $\mathbf{1 8 9 8 b}$ sobre el trabajo de Russell. 
es, pues, esencialmente lo mismo que la medida, y su relación con el número es meramente convencional. Así, tanto en el caso de las cantidades extensivas (relaciones) como en el de las intensivas (atributos) la aplicación del número sólo es factible mediante la hipóstasis del espacio y el tiempo a través de la relación de igualdad (que es también cuantitativa).

De esta forma Russell soluciona el primer problema, es decir, el relativo a la consideración de la cantidad como propiedad intrínseca. Pero lo hace recurriendo todavía a la lógica idealista basada en la minusvaloración de las relaciones. Por eso no puede hacer aún usq del germen del principio de abstracción que, en los manuscritos de 1898-1900 le permitió, después, sustituir las propiedades comunes por relaciones con auténticos términos. Ni puede tampoco plantearse la posibilidad, también realizada en los mismos manuscritos, de reducir incluso la igualdad misma a la identidad de magnitud (aquí llamada todavía "cantidad").

Por ello también vuelve a caer en la "contradicción de la relatividad", tan acorde con el actual ropaje hegeliano, al mantener al mismo tiempo que dos cosas que difieren cuantitativamente no lo hacen conceptualmente y que la cantidad no es una propiedad de las cosas cuantitativas. ${ }^{9}$ Es decir, al mantener "una concepción de la diferencia sin una diferencia de concepción" (1897c, 340). En mi 1988a (y 1991a, cap. 2) expliqué ya que esa contradicción sólo se superaba admitiendo las relaciones externas, que en el trabajo de 1897 no manejaba aún Russell. Sin ellas, se ve obligado a concluir que la idea de cantidad es una manifestación de la inadecuación entre el pensamiento y la sensibilidad. El análisis del continuo queda todavía tan lejano que tendrán que tener lugar aún varios intentos de fundamentación de estos conceptos (los manuscritos previos a 1903a) y la aparición de una nueva influencia (la de Peano) antes de que la aceptación de Cantor fuera posible. El ropaje hegeliano impedía ver que las ideas fundamentales no eran otras que los indefinibles de More.

\section{La obra sobre Leibniz}

En 1900 Russell publicó $A$ Critical Exposition of the Pbilosophy of Leibmiz (en adelante PL), después de haber dado su contenido básico en unas conferencias que tuvieron lugar en el primer trimestre de $1899^{10}$ (aunque hay que des-

9 Contradicción que estaba ya latente en 1897a, como lo hizo ver Couturat en 1898 a al denunciar la incompatibilidad existente entre la consideración de la cantidad (grandeur) como algo inexistente fuera de la comparación, por un lado, y la de los términos como dotados ya de cantidad antes de la comparación misma, por otro. El propio Couturat intentó resolverla en $1898 \mathrm{~b}$ distinguiendo entre magnitud y cantidad y entre constante y variable, rechazando el lenguaje idealista de Russell.

10 O'Briant 1979a, 17l. Aquí, como en otros aspectos relativos a cronología y fuentes, me baso en este trabajo, verdaderamente definitivo al respecto. 
tacar que los trabajos preparatorios tuvieron lugar durante todo el segundo semestre de 1898). Se trata, pues, de un periodo de interés excepcional al corresponderse de lleno con la redacción de los manuscritos a los que me he ido refiriendo anteriormente. ${ }^{11}$

En la obra tuvo que manifestarse necesariamente el estado de su filosofía en aquel momento, que no era otro que la asimilación de Moore, como reconoció posteriormente Russell (al declarar que la obra le sirvió para poner en práctica la nueva filosofía; 1967a, 212). También ha insistido Russell en que fue esa influencia la que le condujo a la doctrina de las relaciones "externas", permitiéndole llegar a la conclusión de que una relación no implica complejidad en los términos relacionados, y no equivale a cualquier propiedad del todo formado: "Justamente después de desarrollar esta posición en mi libro The Philosophy of Leibniz, conocí la obra de Peano ..." (1959a, 10). De hecho, el hablar de la "influencia" de Moore constituye un verdadero eufemismo: todas las herramientas de Russell proceden, en su integridad, de Moore. Sin embargo, el prefacio se limita a una mención vaga de ello.

La importancia de la obra radica, precisamente, en este punto; como señalé en mi 1990e, las características de la filosofía temprana de Moore se concretan, sobre todo, en una articulación tal de lógica y ontología que conduce directamente a la constitución y desarrollo de un método de análisis basado en la presuposición y la definición, cuya influencia en los manuscritos russellianos de 1898-1900 fue masiva. Sin ambargo, PL es la primera obra publicada donde el método se aplica de manera sistemática y explícita.

La literatura apenas se ha ocupado de PL, y mucho menos desde el punto de vista metodológico, ${ }^{12}$ así que mis objetivos aquí son más bien pioneros.

11 Precisamente esos trabajos debieron dificultar la preparación del manuscrito sobre Leibniz, que no llegó a la imprenta hasta casi un año después de terminadas las conferencias (O’Briant 1979a, 174 y nota 58). Sin embargo, entre la lectura de las pruebas y otros retrasos, el libro no salió, al parecer, hasta el último trimestre de 1900 (el prefacio está firmado en septiembre), con lo que Russell aún pudo incluir una nota (al final, p. 299) haciendo referencia a Peano, al que acababa de conocer en el Congreso de París de julio.

12 Sólo hay, que yo sepa, lo siguiente: Wiener 1944a, Bermann 1956a, Carmo 1972a, Körner 1979a y el ya citado O'Briant 1979a, que pretende sólo ofrecer “materiales” para un estudio. Las obras extensas sobre Russell eluden sistemáticamente el tema, como es costumbre con todo el periodo anterior a 1903a (O’Briant, pp. 163-4, denuncia también la situación), salvo el librito de Watling (1970a), que le dedica un interesante capítulo de doce páginas. Y ello a pesar de tratarse de un periodo absolutamente básico para entender el origen del método russelliano y por ello, de toda su filosofía. Si lo que se busca es un estudio sobre el método, entonces la situación es ya desesperada; sólo Wiener parece pretenderlo, pero nada de ello podemos encontrar de hecho en su artículo. En cuanto a Carmo, se trata de una simple y no muy afortunada expasición. El artículo de Bergmann es interesante, sobre todo por que subraya (o sugiere) que la falta de entendimiento de Leibniz por parte de Russell dependió de la incapacidad de Leibniz de aceptar indefinibles, pero contiene más filosofía propia que interés por develar la función de la obra en el desarrollo de Russell. 
Trataré de entresacar exclusivamente lo concerniente al propio Russell; más en concreto, ofreceré un análisis de todos los argumentos que utiliza Russell en sus críticas a Leibniz para aislar, en ellos las tesis metodológicas que presuponen. Como comprobaremos, siempre que Russell manifiesta una postura propia lo hace sirviéndose de alguna de las tesis básicas de Moore, ${ }^{13}$ las cuales tienen sobre todo un interés metodológico. La conclusión puede adelantarse: la influencia de Moore estaba ya plenamente consolidada antes del Congreso de París. ${ }^{14}$

\section{Los postulados}

En PL aparece de nuevo la idea del "doble proceso" de etapas anteriores (1897a y los manuscritos); y lo hace precisamente mediante una aplicación a la propia filosofía de Leibniz. A partir del momento en que Russell descubrió que el inmenso edificio reposaba sobre los fundamentos lógicos del Discurso de Metafisica y las cartas a Arnauld, trató de aislar los presupuestos contenidos en esas obras hasta presentarlos como premisas, de las cuales, afirmó, puede deducirse todo el sistema (PL, xiv). El trabajo debía, pues, descubrir exactamente el "principio lógico" (PL, 9) de toda la cadena de razonamientos con objeto de efectuar toda una reconstrucción que redujese el sistema de Leibniz a unos pocos postulados. Aquí tenemos ya una de las constantes del propio método russelliano. 15

Según Russell, Leibniz no extrajo, por motivos de prestigio social, las consecuencias que se derivan de tales premisas. Su tesis es que cuando esa tarea se lleva a cabo, se ve cómo todo el sistema leibniziano se deduce casi enteramente de ellas ( $\mathrm{PL}, 3$ ), siendo algunas de las cuales tan básicas que dudosamente el propio Leibniz pudo ser consciente de la forma en que las presuponía. Es imposible no ofrecer aquí las cinco premisas: (i) toda proposición tiene un sujeto y un predicado; (ii) un sujeto puede tener predicados que sean cualidades existentes en varios momentos (será, pues, una sustancia); (iii) las proposiciones verdaderas que no afirmen existencia en momentos particulares son necesarias y analíticas (las que no, son contingentes, sintéticas y dependen de

13 Esta particularidad ya ha sido señalada anteriormente (Watling 1970a, 8, y Wiener 1944a, 265 s.) pero hasta ahora nadie había hecho el trabajo relevante para demostrarlo.

14 En mi 1990a mostré que en la polémica con Poincaré se halla prácticamente consolidada tal influencia, al menos en un tema básico: la necesidad de que las definiciones conlleven la intuición de los componentes del definiens.

15 Como ya vio Wiener 1944a (264 s. y 174) Russell presupone, con ello, que existe un "principio lógico" absoluto que no depende, como sucede en la axiomática, de un determinado orden deductivo más o menos convencional. Pero Russell no aceptaba la convencionalidad de los axiomas, como lo muestran sus argumentos contra Poincaré (véase mi 1990a), a pesar de ser ése el lugar donde más se acercó a tal postura: 
causas finales); (iv) el Ego es una sustancia; (v) la percepción produce el conocimiento de un mundo externo, es decir, de existentes distintos de mí y mis estados.

La crítica posterior ha encontrado estas premisas no del todo adecuadas, ${ }^{16}$ sobre todo (como veremos más abajo) las tres primeras, que son más de carácter lógico-lingüístico. Pueden defenderse muchas lecturas de Leibniz que prescindan de ellas, al menos en su presente formulación. También ha sido criticado su número, aunque en esto el propio Russell estaría más inclinado a conceder la razón a la crítica. (Parkinson 1965a, pp. 184-5, ha mostrado cómo 13 definiciones, 7 axiomas y 21 teoremas pueden dar cuenta del sistema de Leibniz.) Es de destacar que en la obra de Russell falten los indefinibles, sin embargo la cadena de transiciones parece dejar claro que son los contenidos en las cinco premisas, las cuales, a medida que se van articulando, cumplen el papel de las definiciones explícitamente formuladas. Por tanto el método de 1897a se repite en el nuevo estilo.

Más interesante es el problema de la inconsistencia. Russell mantiene, por un lado, que el sistema de Leibniz se deduce correcta y necesariamente de las cinco premisas (PL, 3-4) y, por otro, que estas llevan a contradicciones, por lo que una o más son falsas (PL, 4). Ya Wiener (1944a, 264) escribió al respecto que si las premisas eran falsas cualquier conclusión pudo probarse a partir de ellas. La respuesta de Russell (1944b, 695-6) consistió en precisar el hecho de que aun cuando la proposición falsa implique a cualquier otra, no se sigue que las proposiciones así deducidas queden "probadas", sino que la verdad de las proposiciones ha de establecerse independientemente.

Körner (1979a, 172) ha insistido sobre el mismo punto argumentando que cualquier sistema se deduciría, si se admite la inconsistencia, de las cinco premisas, por lo que no habría mérito alguno de carácter lógico en Leibniz (como pretendía Russell). Conviene advertir, sin embargo, que el susodicho mérito, si está fuera de lugar, no es a causa de la supuesta inconsistencia, sino de que, como Russell reconoció, el propio Leibniz no fue consciente de las premisas como tales, por lo que mal pudo llevar a cabo deducción alguna. Lo que pretendía Russell era sólo poner de manifiesto su admiración por el sistema completo a pesar de que bajo el microscopio pudieran aparecer inconsistencias concretas (sobre todo al cambiar el "orden lógico").

Asimismo hay que recordar que en esta etapa la noción de implicación estaba en formación en la lógica de Russell (véase mis 1988a y 1991a), por lo que resulta anacrónico homologarla con los cánones posteriores, lo que no advierten Wiener, Körner, ni el propio Russell en su respuesta. Una muestra más de lo imprescindible del punto de vista histórico (Körner llega a hablar de "la" lógica de Russell, como si existiera tal cosa). En ese momento Russell sólo

16 Véase Watling 1970a, 10; Serres 1968a, 26-7 y Parkinson 1965a, 183. 
tenía claro que la implicación es una relación indefinible incapaz de ser explicada, ni siquiera recurriendo a los valores veritativos. En cuanto a la relación entre premisas y conclusión, se hallaba completamente en duda sobre si existe entre ellas implicación mutua o no (ya que los axiomas, al ser más simples, se hallan presupuestos en los "teoremas"). Como pudimos comprobar todo ello se debió, en parte, a la utilización de los conceptos que configuraban las proposiciones como criterios de simplicidad en virtud de su mayor o menor generalidad (con el problema que esto hacía surgir con relación al todo). De nuevo aparece la necesidad de situar los textos de Russell en su lugar histórico.

\section{Las transiciones}

También en PL encontramos que los postulados a priori se "aplican" a lo existente mediante una serie de transiciones que van de lo general a lo más concreto. Como Kant, Hegel, Hannequin, Hertz o Whitehead, y también como en 1897a y los manuscritos, se partirá aquí de unas proposiciones que, mediante un proceso de particularización (antecedente de la interpretación semántica) van haciéndose "existenciales". En el caso de las 5 premisas esto no se cumple tan claramente en las dos últimas (que parecen involucrar ya existentes) pero puede mantenerse el esquema general si consideramos que ellas mismas son ya "particularizaciones" de las primeras. ${ }^{17}$

El esquema parte de unas ideas muy generales que, mediante la adición de otras más y más particulares, van "encarnándose" y, por tanto, dando cuenta de ámbitos cada vez más concretos, de manera parecida a aquella en que, en los manuscritos (y en Whitehead 1898a), aparece el mecanismo incipiente del logicismo (véase mi 1990d). Las ideas generales son aquí las 5 premisas, que constituyen "la lógica" de Leibniz y su epistemología. A partir de ellas se da paso al mundo externo, es decir, al espacio y al tiempo. Russell divide el proceso en tres fases que, en conjunto, presentan la teoría de las mónadas "como una rígida deducción de un pequeño número de premisas" (PL, xiv), más bien que como el principio "metafísico" del sistema.

La primera fase (caps. II-V) está constituida por las cuatro primeras premisas, más todas las proposiciones que pueden deducirse de ellas, lo que constituirá la "parte necesaria de la filosofía de Leibniz" (PL, 9) y comprenderá: el principio de contradicción, el de razón suficiente, la teoría de la sustancia, la identidad de los indiscernibles, la ley de continuidad y la teoría de la posibilidad. La primera transición (de la primera fase a la segunda) supone el abandono de las discusiones "lógicas" (PL, 69) y el paso a la filosofía de la

17 Dejando de lado, claro está, la cuestión, también anacrónica, de la “independencia” de los axiomas. Hilbert había publicado ya su $1899 \mathrm{a}$, pero parece que Russell no los conocía (incluso en 1903a apenas los menciona). 
materia, de la cual, se nos dice, Leibniz dedujo la doctrina de las mónadas (haciendo intervenir la quinta premisa, que abre el paso al mundo externo). Así se abre un nuevo orden de ideas donde las cuestiones acerca de la naturaleza de las proposiciones y la definición de sustancia dan paso a otras referentes a lo existente: “¿cómo puede la noción de sustancia aplicarse al mundo de lo existente? ¿Hay una sustancia o muchas?” (PL, 70).

La segunda fase (caps. VI-XI) se dedicará, pues, a la descripción y "prueba" del monadismo, en la medida en que éste sea independiente de las causas finales y de la idea de bien, que pertenecen a la tercera fase. También en esta segunda fase tendrá lugar una transición (o "transformación”): aquella mediante la cual los significados "puros" de la materia, tal y como ésta es presupuesta por la extensión y exhibe la fuerza, pasan a "encarnarse" en otros, los relativos a la naturaleza de cada mónada creada (y, como "masa", a los agregados de ellas): "La transformación del primer par de significados constituye la prueba de la doctrina de las mónadas" (PL, 76). Así se explica el paso de la dinámica a la continuidad, la extensión, las mónadas, el espacio y el tiempo. La segunda transición (de la segunda fase a la tercera) consiste en el paso de las mónadas puras y aisladas a las relaciones entre ellas y, con ello, a la aparición de los cuerpos y las almas, lo que exige la introducción de una nueva idea: la de pasividad (PL, 139), en la que se concreta la nueva particularización. El "logicismo" incipiente aparece cuando Russell habla de la necesidad de explicar todo ello "en términos de mónadas" (PL, 138).

El método usado ejemplifica tanto la búsqueda de un orden lógico como el antipsicologismo de Russell. En ambos casos se evitan las consideraciones fácticas y se busca la verdad de las relaciones lógicas: en el caso de la matemática, atendiendo a las relaciones "puras" entre los conceptos; en el de los sistemas filosóficos (como el de Leibniz) evitando las consideraciones personales (los "motivos"), que son explícitamente declaradas irrelevantes para la verdad o falsedad, tanto como para la corrección lógica (PL, xii). Precisamente por esta razón reprocha Russell a Leibniz como su más grande error el haber confundido "el orden lógico" con "el orden de prueba o descubrimiento" (PL, 101) al relacionar la sustancia con el espacio, es decir, el haber tomado el orden psicológico (para nosotros) con el orden de la prioridad lógica (en sí).

Sin embargo Russell no pudo admitir, por su kantismo, una de las ideas más fructíferas de Leibniz: la de que la extensión y el espacio se derivan de la sustancia y no, como quería Kant, a la inversa (dado que para él la sustancia se infiere de la extensión y ésta presupone el espacio) (PL, 101-2). Por motivos parecidos, Russell rechazó también el carácter analítico de la lógica y la matemática (véase más abajo) y el que ambas sean a priori en relación con 
las ciencias de la naturaleza, ${ }^{18}$ En esta cuestión el logicismo de Leibniz fue mucho más avanzado que el de Russell.

\section{La teoría del juicio}

La "lógica" de Russell en esta etapa se hallaba constituida en lo fundamental por una teoría acerca de la naturaleza del juicio y de la forma más correcta de efectuar el análisis de sus componentes (el “cálculo lógico" cumplía otra función). En ello seguía de cerca las enseñanzas de Bradley y de Moore; como para ellos, la teoría del juicio era la base de toda su filosofía: "Que toda sana filosofía debería comenzar con un análisis de las proposiciones es una verdad demasiado evidente, quizá, para exigir una prueba. Que la filosofia de Leibniz comience con tal análisis es menos evidente, pero parece no ser menos cierto" (PL, 8). Esta óptica, que es el resultado de su inserción en un contexto filosófico muy concreto, le hace ver como básicos y urgentes en Leibniz problemas que, por otra parte, admite de dudosa conciencia por parte del filósofo. ${ }^{19}$

Russell defiende las siguientes tesis: que no toda proposición es asimilable al esquema sujeto-predicado; que Leibniz mantuvo lo contrario: que, de acuerdo con ello, trató de reducir el resto de proposiciones a tal esquema y que, sin embargo, las proposiciones relacionales y los juicios de existencia escapan a esa reducción. Como me referiré a los dos últimos puntos en secciones posteriores, dejaré aquí constancia sólo de la forma en que la oposición a Leibniz se realiza desde la teoría relacional del juicio de Moore. El texto más relevante es el siguiente (PL, 15; las cursivas son mías salvo al final):

Una discusión completa de la presente cuestión procedería, en este punto, a mostrar que los juicios de sujeto y predicado son en $s i$ mismos relacionales e incluyen, además, como se entienden habitualmente, dos tipos de relación fundamentalmente diferentes. Estos dos tipos resultan ilustrados por las dos proposiciones:

18 Véanse los textos relevantes de Leibniz, por ejemplo en Martin 1960a (117-8 y 120-1).

19 Una prueba adicional de la influencia del aparato lógico de Moore la tenemos en un boceto inédito del orden a seguir (en O'Briant 1979a, 168). En él estaba previsto comenzar por los grandes principios lógicos de Leibniz, que son calificados de "premisas", aunque sin referirse para nada a las "premisas lógicas" que, procedentes del análisis de la proposición, incluyó después como principios lógicos absolutos en PL. En adición, se incluye la "lógica” al lado de la epistemologia ( $\mathrm{y}$ después de la metafísica). Cabe, desde luego, pensar que tal asociación responde al mismo motivo que le hizo incluir el apartado sobre la characteristica universalis en el capítulo sobre ta teoría del conocimiento (en PL), considerando, así, ta lógica como integrada sólo por un cálculo. Aunque así fuera, volvería a confirmarse nuestro aserto referente a la creciente influencia de Moore, pues no de otra forma cabe interpretar el hecho de que primero entendiera la lógica como cálculo y después como teoría del juicio. Así, la influencia de Whitehead palidecía ante la más filosófica de Bradley y Moore. 
"esto es rojo" y "rojo es un color". Al mostrar que estas dos proposiciones expresan relaciones se mostraría que la relación es más fundamental que los dos tipos especiales de relación implicados.

Con respecto a la división entre dos tipos de relación básicos, Russell explica en otros lugares de la obra (ej. en p. 17) que el primero se refiere a la "pertenencia" (por expresarlo en términos actuales, a pesar de que sólo con Peano, Russell descubrió la importancia de la distinción técnica) de un miembro a una especie y el segundo a la "inclusión" de una especie en un género. Lo que sirve de base a la lógica para insistir en el carácter existencial del primero (que involucra la referencia al tiempo y al espacio) y el carácter "esencial" del segundo (que supone una relación inmutable entre conceptos). De esta forma el pluralismo de Moore se muestra como el mejor aliado de las relaciones externas. El que (como creía Russell) Leibniz defendiese el primero y rechazase las segundas desde el esquema predicativo constituyó, sin duda, una posibilidad lógica desafiante.

La teoría relacional del juicio tiene otras consecuencias, si continuamos siguiendo a Moore. Si los componentes de la proposición son siempre sujetos lógicos (o conceptos), entonces también la existencia y la verdad lo serán y no habrá manera de mantener (en lógica) juicios existenciales ni posibilidad alguna de comparar un juicio con la realidad empíricamente considerada. Entre otras cosas porque la percepción conlleva necesariamente un juicio e incluso los "particulares egocéntricos" (como Russell los llamó en obras posteriores), como "nombres lógicamente propios", esconden, como mínimo, descripciones (esto era así ya para Bradley; véanse mis 1989 b y $1990 f$ ). Por consiguiente la teoría relacional del juicio será una alternativa tanto para la "teoría existencial del juicio" (que defiende la existencia de los componentes) como para la teoría de la verdad como correspondencia. De acuerdo con ello, tanto la existencia como la verdad serán conceptos como los demás; cuando se dan, exhiben el sujeto lógico correspondiente en relación con los otros conceptos del juicio.

Las críticas a las pruebas de la existencia de Dios son un campo privilegiado para usar todos estos recursos. El argumento ontológico (PL, 174 75) es fácil de destruir con sólo constatar que únicamente puede identificarse lo existente con lo necesario desde una teoría "analítica" del juicio, es decir, desde una teoría que permita, adoptando el esquema sujeto-predicado, que un concepto absorba a otro y destruya su carácter de término subsistente. La teoría relacional se hace, así, garante de la imposibilidad de rebasar con trucos "formalistas" 20 la barrera entre el ser y la existencia. La crítica al argumento

20 Me sirvo aquí de un vocabulario anacrónico por recordar el parecido del intento de Leibniz por considerar lo posible, entendido como lo carente de contradicción, como paso hacia lo existente y lo necesario. 
cosmológico (PL, 175 ss.) muestra lo mismo pero con mayor claridad aún: también para partir de la existencia de algo como dato es necesario presuponer la teoría existencial del juicio. Cuando se afirma que todos los existentes finitos están condicionados por otro de ellos, mientras la serie completa no lo está (convirtiéndose así ésta en metafísicamente necesaria), se está rebasando de nuevo el abismo entre lo meramente existente en el tiempo y lo verdaderamente necesario, que es subsistente e inmutable.

Aquí Russell se sirve de un argumento extraído de Bradley para mostrar cómo la validez del que está criticando depende de la admisión de la teoría existencial del juicio (PL, 177):

Mantener que no hay verdad es auto-contradictorio pues, si nuestra afirmación fuera ella misma verdadera, habría verdad. Entonces, si toda verdad consiste en proposiciones acerca de lo que existe, es auto-contradictorio mantener que nada existe. Así la existencia de algo es metafisicamente necesaria.

Ello nos conduce, por su asociación entre existencia y verdad, al argumento de las verdades eternas (PL, 177 ss.), cuya crítica ejemplifica a la perfección la nueva lógica, sin duda por ser el ámbito donde se ve con mayor claridad cómo la verdad se hace depender del conocimiento mientras que, como decíamos antes, es en realidad un concepto subsistente, independiente de todo conocimiento, incluido el de Dios. La dependencia de la teoría existencial es aquí muy clara: al hacer depender la verdad del conocimiento que de ella se posea, se presupone que lo que no existe no es nada; pero la verdad es algo y, por tanto, existe, y como el conocimiento también existe, "la proposición de que una proposición dada es verdadera se reduce a la proposición de que ella es conocida y, así se convierte en existencial". ${ }^{21}$

21 Los materiales publicados por O'Briant 1979a no hacen más que confirmar lo dicho. De las "Notes on Leibniz" destaca este comentario sobre un texto de Leibniz en el que se situaban las verdades eternas en la mente de Dios: "not the truths, but the knowledge of them, is in God's mind, and this implies that the truths are truely independently of God. A truth, in any case, cannot exist" (ibid., 167). He aquí también dos fragmentos de cartas relevantes: el primero pertenece a una carta a Stout de 23-9-1900 y en él Russell confiesa mantener la teoría del juicio de Moore: "It will be some time before I am rash enough to expound my (or rather Moore $\$$ ) theory of judgment: indeed unless he grows completely idle, I shall Leave it to bim, as he und erstands it better than I do, and is its inventor" (ibid., 198 nota); el segundo está extraido de una carta a Bradley de 16-11-1900 (como el anterior, ambos son posteriores a la terminación de PL) y aclara la teoría relacional: "my contention is that, in most propositions, thare are two or more real subjects: and that the attempt to be content with one subject mecessa rily destroys the essmee of ma ny propositions -for instance, such as ascert relations of greater and less, or of whole and part" (ibid., 192). Debió ser curioso para Bradley recibir una explicación tan dependiente de su propia teoría del juicio (véase mi 1990). 


\section{Lo analítico y lo sintético: Couturat de nuevo}

La presente distinción es kantiana y no fue utilizada por Leibniz. Al menos en este sentido; sin embargo Russell la utilizó profusamente en PL atribuyendo al propio Leibniz su asimilación a la distinción necesario-contingente. Las consecuencias de tal paralelismo, aunque no parecen buenas para una correcta comprensión de Leibniz, nos ofrecen nuevos puntos de penetración en la propia filosofía de Russell. Para éste (PL, $\$ \S 11-12$ ) hay que partir del rechazo de lo "analítico": todas las proposiciones son relacionales y, por tanto, sintéticas. Las aparentemente analíticas son tautológicas y, por ello, no son proposiciones. En cambio, para Leibniz las proposiciones sintéticas, es decir, aquellas de carácter existencial, son, según Russell (en PL) contingentes, mientras que las analíticas fundamentarían la lógica y las matemáticas.

Según Leibniz, escribe Russell (PL, 20 ss.), los objetos definidos deben mostrarse primero como posibles, pero como para él lo posible es lo nocontradictorio, entonces todos los predicados simples serían compatibles. Y, como toda idea se divide, últimamente, en simples, todas las ideas serían posibles. De esto Russell obtiene la conclusión de que tal relación de compatibilidad habrá de ser necesariamente sintética ya que, para ser analítica, al menos una idea tendría que ser compleja (el "sujeto"). De ahí que si no hubiesen relaciones sintéticas de compatibilided (o incompatibilidad) todas las ideas complejas serán igualmente posibles. Por tanto, en toda definición se presupone la proposición, sintética, de que los constituyentes simples son compatibles. Volvemos así, de todas formas, a Kant: "Una idea posible no puede, en último análisis, ser meramente una idea no contradictoria: pues la contradicción misma debe siempre ser deducida de proposiciones sintéticas. De aquí que las proposiciones de la Aritmética, como Kant descubrió, sean todas sintéticas" (PL, 21).

A partir de ahí la negativa a identificar lo necesario con lo analítico es ya fácil; no hay más que utilizar la filosofía de Moore para, a través de su identificación de lo a priori con lo presupuesto y su reducción de la existencia y la verdad a meros sujetos lógicos independientes (como todos) de nuestro conocimiento de ellos, llegar a la conclusión de que no hay barrera "lógica" entre lo empírico y lo a priori. Todo juicio es, pues, necesario ${ }^{22}$ y sintético y la relación entre sus conceptos objetiva:

Kant, al señalar que los juicios matemáticos son a la vez necesarios y sintéricos, preparó el terreno para la postura de que ello es verdadero de todo juicio. La distinción de lo empírico y lo a priori parece depender de la confusión entre fuentes

22 Russell, sin embargo, no tenía claro el concepto de necesidad, por lo que, como es costumbre en él, opta por declararlo "último c indefinible" (PL, 23). Una de sus primeras reacciones al Congreso fue "Necessity and Possibility" (m 1902?), donde coquetea con la teoría de lo analítico propuesta por Couturat a la que en seguida me referiré en el texto. 
del conocimiento y bases de la verdad. Sin duda hay una gran diferencia entre el conocimiento obtenido mediante la percepción y el conocimiento obtenido mediante el razonamiento: pero ello no muestra una diferencia correspondiente con respecto a lo conocido.

Teniendo en cuenta todo esto, Russell desarrolla una explicación del principio de razón suficiente que interesa porque ilustra bien su necesidad de huir de lo analítico y también porque sirvió de base para una posterior polémica con Couturat de importantes consecuencias. Diré algo sobre cada uno de estos puntos.

La única posibilidad de distinguir los juicios necesarios de los contingentes ha de radicar, si rechazamos, con Russell, los juicios analíticos, en el criterio de lo existente. Así puesto que las proposiciones necesarias no son las que se siguen del principio de contradicción, sólo podemos restringirlas al ámbito de lo no existente bajo la óptica de que las proposiciones que afirman existencia no son nunca necesarias. Se trata, claro es, de un criterio convencional, pero le sirve a Russell para presentar el principio de razón suficiente como el nexo que permite unir las proposiciones existenciales (PL, $\S 13$ ).

Sin embargo, como no puede entender que la formulación habitual "nada es sin razón” llegue a depender exclusivamente del principio de contradicción (lo que al parecer impediría dar cuenta de los procesos causales) y se da cuenta de que para Leibniz también lo contingente puede probarse a priori (en Leibniz a priori se opone a empírico y no a contingente), opta entonces por distinguir entre dos tipos de razones suficientes (PL, $\S 14$ ). Uno de ellos, aplicable tanto a lo posible como a lo actual, diría que todo suceso se debe al designio divino. En esta forma el principio sería necesario y analítico, es decir, una consecuencia del principio de contradicción, ya que todo mundo posible ha de regirse por algún designio de Dios (que los ha creado todos). En cambio el otro tipo, aplicable sólo a lo realmente existente, está coordinado con el principio de contradicción (lo que para Russell significa que ambos son independientes lógicamente, es decir, incapaces de ser deducidos uno de otro) y origina el mundo tal y como es: la finalidad y lo bueno lo determinan (PL, $\S 5)$.

Aquí puede verse claramente que Russell consiente en considerar el principio de razón suficiente como analítico cuando es referido sólo a los mundos pasibles, confiando con ello en que la extraña fusión de lógica y matemática que según Leibniz tenía lugar en la mente de Dios pudiese superar la vacuidad de lo tautológico. Por tanto su esquema continúa siendo el mismo: en nuestro mundo lo necesario es lo analítico, y lo contingente lo sintético; las proposiciones existenciales son sintéticas y el principlo de razón suficiente tiene un lado lógico según el cual puede deducirse del principio de contradicción. 
Cuando PL llegó a manos de Couturat, que ya había publicado su obra sobre la lógica de Leibniz y estaba preparando su edición de los inéditos, todo ese esquema fue dinamitado, como muestra su correspondencia mutua y los artículos que publicaron sobre el tema. ${ }^{23}$ De hecho se trata de una polémica posterior al Congreso, por lo que la influencia de Peano estaba ya latente; me limitará aquí, pues, al tipo de cambios que provocó en la interpretación russelliana de Leibniz y a la forma en que esto ilustra sus concepciones.

Según Couturat el principio de razón suficiente significa, simplemente, que "toda verdad es analítica" siendo así el complemento del principio de contradicción: “toda proposición analítica es verdadera” (carta de 5-6-1901, en O'Briant 1979a, 205). La justificación del aparentemente paradójico significado es, sencillamente, que las relaciones fácticas entre los acontecimientos que tienen lugar en el universo, aunque históricas (empíricas) para nuestro entendimiento finito, son transparentes para Dios, que ve el pasado y el futuro. ${ }^{24}$ Como consecuencia de ello también las verdades contingentes han de considerarse analíticas, incluyendo las existenciales.

Russell se resistió (2-10-1901, ibid. 206-7) a tal interpretación alegando la compatibilidad entre su propia postura y los textos relevantes e insistiendo en su famosa distinción entre matemáticas y filosofía a través de una visión "filosófica" de la lógica (mientras para Couturat la lógica era, básicamente, el cálculo lógico). Couturat intentó minar la resistencia de Russell (4-10-1901, ibid. 207) sin obtener el beneplácito de este, pero entre tanto se publicó 1902a de Couturat, que contenía el opúsculo Primae veritates de Leibniz junto con una serie de fragmentos y argumentos. En el opúsculo se ve cómo, ciertamente, toda la metafísica de Leibniz se deduce, explícitamente, del principio de razón suficiente, entendido a la manera de Couturat. Además, Couturat acusó a Russell de confundir Leibniz y Kant al hacer de la existencia un predicado excepcional cuya afirmación sería sintética (1902a, 13), aparte de insistir en que, como las verdades contingentes no son sintéticas, es necesario admitir que para Leibniz una proposición analítica puede no ser necesaria (1902a, 11).

23 La correspondencia relevante está publicada en O’Briant 1979a (traducida al inglés); los artículos relevantes son Couturat 1902a y Russell $1903 \mathrm{~b}$.

24 En su primera carta, anterior incluso a PL (5-5-1900; O'Briant, ibid., 202), Russell manifiesta su sorpresa por la coincidencia en la interpretación pero, cuando Couturat atribuye el paralelismo (13-5-1900, ibid., 203) a la influencia de Whitehead, Grassman y Boole, Russell protesta (21-6-1900, ibid.) aferrándose a su muy querida diferencia entre matemática y filosofia: "As for Leibniz I see that our two books scarcely say the same thing; the subject which you bave chosen interests me cnomously, but I beliepe (as you said in your article on Whitehead) that the characteristic is rather a mathematical idea than a philosopbical one". Cabe recordar aquí, sin embargo, que precisamente la recesión de Couturat a la que se refiere Russell realizaba una interpretación abiertamente logicista de la famosa obra de Whitehead. 
Russell se rindió, finalmente, a todo ello: ${ }^{25}$

Sus citas me convencieron sobre el asunto del principio de razón y los juicios de existencia. Yo citaba en mi libro varios textos que son difícilmente suscepribles de alguna otra interpretación, pero no fui capaz de suponer que se pueden tomar los juicios analíticos por contingentes. Por esta razón, es la cita que usted hace (...) y que comienza "Itas arcanum aliquod" la que finalmente me persuadió de la corrección de su teoría.

Es indudable que la resistencia de Russell se relaciona sobre todo con su descalificación de lo analítico como lo meramente tautológico. Si una proposición está, en contra de ello, llena de contenido fáctico (e incluso histórico), no puede no afirmar nada. En consecuencia, el solo hecho de admitir la posibilidad de que las proposiciones contingentes fueran analíticas (aunque se tratase de Leibniz) le obligaba a "imaginar" a estas últimas corno auténticamente informativas.

La polémica con Couturat supuso el mayor desafío a la identificación russelliana de lo analítico y lo tautológico que, por sí misma, descalificaba todo lo no sintético. Años más tarde Russell admitiría, bajo la influencia de Wittgenstein y los positivistas lógicos, que la matemática es, en conjunto, una vasta tautología e incluso algo cuyo contenido veritativo no pasa de ser meramente "lingüístico" (véanse mis 1990d y 199la). Pero en este momento da la sensación de que sus pegas contra Leibniz sean las que todavía tiene contra el logicismo, entendido éste como la reducción de la matemática a una logica cuyos indemostrables sean meras tautologías. Sin duda la distinción entre matemáticas y filosofía coadyuvó a la supervivencia de la influencia kantiana, por cuanto hacía necesaria la intuición para descubrir los indefinibles e indemostrables. En todo caso el carácter sintético de todas las proposiciones genuinas (sean de un tipo y otro) procedía, como hemos visto, de la teoría relacional del juicio de Moore; y, a pesar de ser mantenido todavía en la recensión a Couturat, ${ }^{26}$ hay motivos para pensar que la sugerencia de este último fue seguida, al menos en algunos manuscritos (especialmente en m 1902?). ${ }^{27}$

25 Carta del 23-3-1902 (ibid, 208). El fragmento de Leibniz aludido por Russell en la cita que transcribo dice: “Atque ita arca num aliquod a me crobutum puto, quod me diu perplexum babuit, non intelligentem, quomodo praedicatum subjecto inesse posset, nec tamen propositio fieret necessaria. Sed cognitio rerum geometricarum atque anafysis infinitorum bane mihi lucem accendere, ut intelligerem atiam notionos in infinitum resolubiles ese" (Couturat 1902a, 11, nota 3). Ishiguro 1972a (p. 122 ss.) también lo cita y lo comenta.

26 Russell 1903b, 187. Y ello a pesar de dar la razón a Leibniz sobre Kant en lo tocante a la relación entre matemática y filosofia (p. 192).

27 Como ya advertí al principio de la sección, me desentiendo explícitamente de la literatura sobre Leibniz. La interpretación de Couturat (que pasó a ser la de Russell) ha sido desautorizada por Ishiguro 1972a (120 ss.), y el tema de los juicios de existencia es provechosamente tratado en 


\section{La noción de sustancia}

El punto de partida de Russell ahora es: “iqué es la noción de sustancia?, y no ¿qué juicios sobre el mundo pueden hacerse con ayuda de esta noción?” (PL, 40). La idea básica de Russell, de acuerdo con la visión kantiana subyacente a sus transiciones, es la de demostrar que en Leibniz el recurso al tiempo está ya presupuesto en su noción de sustancia, a pesar de que el propio Leibniz intentó explícitamente sustituirlo por el concepto de actividad, indudablemente llevado por su deseo de presentar el tiempo como un mero ens rationis. Para lograrlo, Russell se sirve, sistemáticamente, de herramientas mooreanas. Veamos los tres momentos básicos.

En primer lugar, se niega a aceptar que la sustancia signifique sólo substratum, con el argumento (basado en la importancia típica que Moore daba al lenguaje ordinario como criterio de significado y, como siempre, de acuerdo con el referencialismo) de que hay otro elemento en el significado que la gente ha atribuido siempre a la palabra "sustancia" (PL, 42): la persistencia en el tiempo. Admitiéndolo, el tiempo se incrusta en el esquema sujeto-predicado, por lo que la noción de sujeto del cambio resulta ser subsiguiente a tal esquema. En suma: la sustancia es aquello que sólo puede ser sujeto y persiste a lo largo del tiempo (PL, 43).

En segundo lugar Russell pasa a atacar la noción misma de actividad, que Leibniz presentó como consecuencia de la sustancia. Como esta última es independiente del exterior y envuelve, de una vez por todas, el conjunto completo de sus predicados históricos, ha de concederse la existencia de algo que proporcione la tendencia a pasar de un estado a otro. Y ese algo debe ser interno, a riesgo de vulnerar la independencia de las sustancias. Aquí Russell se sirve de las relaciones externas (consecuencia de la teoría relacional) para apresurarse a acusar a Leibniz de convertir la relación de causalidad en un atributo de las sustancias, es decir, de participar en la creencia de que "toda relación debe ser analizable en adjetivos de los términos relacionados" (PL, 46).

Por último, el problema de las relaciones internas se aborda indirectamente mediante el interrogante: ‘cómo difieren, según Leibniz, una sustancia de la suma de sus predicados? (PL, $\S 21$ ). Según Russell, Leibniz no identificaba la sustancia con la suma de sus estados ya que, puesto que la experiencia accede sólo a estos últimos, la base del establecimiento de aquella debe ser puramente lógica. Es decir, debe provenir exclusivamente del esquema sujeto-predicado. Pero, continúa Russell, hay dos clases de proposiciones sujeto-predicado: las contingentes ("esto es un hombre") y las demás ("el hombre es racional").

Martin 1960a (p. 53), Parkinson 1965a (36 ss. y 186) e Ishiguro 1972a (72 ss.). No dispongo de espacio para entrar en ello, por lo que me limito a estudiar la importancia del tema para la evolución del propio Russell. 
De ellas, las primeras, que podrían dar pie al establecimiento directo de sustancias (el “this"), fallan en última instancia. Pero “this" debe significar algo, y ese significado debe envolver alguna referencia al espacio y al tiempo, y estos, según Leibniz, son en última instancia reducibles a predicados: "Así, la sustancia permanece aparte de sus predicados, totalmente destituida de significado" (PL, 50).

Por tanto, concluye Russell, de hecho Leibniz confunde la sustancia con la suma de sus predicados, provocando, así, la indistinción entre sujeto y predicado (si los sujetos no son más que sumas de predicados la distinción desaparece). En el apartado siguiente veremos cómo Russell profundiza en el tema de las relaciones en conexión con los indiscernibles y cómo utiliza, para ello, la doctrina mooreana de la diferencia numérica (que ya es implícitamente utilizada aquí).$^{28}$ Es de destacar también el uso que hace Russell de conceptos bradleinianos (el "this") a pesar de rechazar abiertamente su noción de sustancia. ${ }^{29}$

\section{Relaciones $\mathrm{e}$ indiscernibles}

En lo que antecede nos hemos referido ya a las relaciones. Básicamente podemos decir que constituyen el bastión lógico desde el que Russell combate, siguiendo a Moore, el esquema sujeto-predicado a partir de la irreductibilidad de aquellas a éste. En realidad la asociación entre el pluralismo y las relaciones externas venía ya de Bradley (véase mi 1990f). De ahí que Russell, incluso antes de su conversión a la filosofía de Moore, estableciera ya

28 También en este punto la literatura sobre Leibniz ha desautorizado a Russell. Ishiguro (1972a, 103 n.), por ejemplo, niega que para Leibniz una sustancia sea la suma de sus predicados, sobre la base de que para él ningún conjunto de universales puede ser una entidad. En todo caso si Russell insiste en tal postura es porque, al menos en PL, estaba convencido de que había que rechazar toda posibilidad de admitir juicios analíticos: por ello, no se le ocurrió (como veíamos en el apartado anterior) que para Leibniz los juicios concernientes a lo existente pudiesen ser también analíticos. La teoría relacional obligaba a Russell a mantener que la identificación entre sujeto y predicados era un error lógico pues en toda proposición tanto el sujeto como el predicado son sujetos lógicos. Por eso escribió que si efectivamente el sujeto se identifica con sus predicados "predications concerning actual substances would be just as analytic as those concerning csences or specias" (PL, 50). Watling 1970a (p. 18) escribe certeramente al respecto: "since Russell could not credit Leibniz with the view that propositions about individual substances are anabytic be did not do justice to Leibniz's notion of substance".

29 Bradley protestaba de ello en cartas que se han perdido. Sin embargo, las respuestas de Russell se conservan (en O'Briant 1979a, 191-2). En ellas Russell se muestra muy respetuoso, disculpándose explícitamente por no haber entendido justamente las doctrinas del viejo maestro (cosa que en público no admitió jamás). Escribe Russell que, con respecto a Bradley todas las dificultades provienen de su noción de Realidad: "It is not a concept, it rould secm to be nothing; if it is a concept, it does not give Reality a unique logical position" (sobre la dualidad referida véase mi 1990f). 
claramente como posibilidad "lógica" esa salida. ${ }^{30}$ Sin embargo para Bradley toda diversidad debía ser "de contenido", con lo que se refería a una profunda realidad (el "what") que subyacía a todo conjunto de predicados. ${ }^{31}$ Por ello Moore debió dar primacía a la diversidad puramente numérica, establecida entre los sujetos lógicos como tales. Como, según Russell, Leibniz con sus indiscernibles presuponía ambas doctrinas, al decir que dos sustancias difieren siempre también en sus predicados, entonces la diversidad numérica será el arma a utilizar ahora, sobre todo en conexión con la lógica de las relaciones externas.

Para Russell (PL, § 25) sólo pueden negarse los indiscernibles “si sujeto y predicado es la forma canónica de las proposiciones” (PL, 58). Pues, como hemos visto, de admitir el tipo de sustancia de Leibniz, sus diversos predicados se hallan contenidos de forma que cualquier relación de diferencia se convertiría en un mero predicado común. Pero el modelo sujeto-predicado lleva, en última instancia, al monismo. Ya que no cabe plantearse la diferencia de predicados sin admitir, antes, qué es lo que difiere, y eso es ya la diferencia numérica. Está claro que para que dos sustancias dejen de ser indiscernibles debemos asignarles predicados, pero ello no es posible a menos que sean antes distinguidas. En consecuencia, según Russell, si Leibniz hubiese sido consecuente, habría terminado admitiendo a Spinoza. Ambos, en todo caso, desconocieron la otra posibilidad implícita en el reconocimiento de las relaciones externas tal y como éstas se infieren de la teoría relacional (PL, 59).

Consecuentemente, Russell se apresta a extraer la última consecuencia: la destrucción del concepto de sustancia a partir de ese esquema relacional. El complejo argumento (PL, 59-60) podemos resumirlo en forma de círculo vicioso: o la sustancia carece de sentido y no puede distinguirse de cualquier otra, o es una mera suma de predicados. Esta conclusión de Russell constituye el climax de su teoría relacional y pone de manifiesto la estrecha conexión que, entre las relaciones externas y la teoría referencial, se hace necesaria para la destrucción de la noción tradicional en favor de los "conceptos" (o "terminos") de Moore: ${ }^{32}$

30 Spadoni 1977a (p. 180) reseña un ensayo inédito de 1897 donde claramente se opone el pluralismo al monismo con base en las relaciones, aunque sólo sea en forma condicional: "If the world contains simple and substantially unanalyzable elements, then a distinction can be drawn between their natures, and their references to other sponads... In such a case, epery monad would bave an essence consisting of adjectives, but exhibited only in relations". El ensayo es "Why do we regard Time, but not Space, as necessarily a Plenum?".

31 No hay más remedio que asumir el "fantasma” de Bradley que Moore y Russell se crearon si queremos entender sus filosofías. Pero Bradley jamás hubiese admitido que el "contenido" de una realidad fuese separable de su existencia.

$32 \mathrm{PL}, 60$. Incidentalmente, sienta las bases para los problemas que generaron la teoría de las descripciones. Aquí incluso está ya implícita la eliminación del "falso" término sustancia en 
Estas dificultades son el resultado invariable de admitir, como elementos de las proposiciones, cualesquiera términos que se hallen destituidos de significado, es decir, cualesquiera términos que no sean lo que puede llamarse ideas o conceptos. Contra muchas sustancias podemos argumentar (urge), con Mr. Bradley, que toda diversidad debe ser diversidad de significados; contra una sustancia podemos argumentar que lo mismo es verdadero de la identidad. Y esto se mantiene igualmente contra la supuesta auto-identidad del la Realidad de Mr. Bradley.

El ataque a la sustancia es, así, completo. De forma que el esquema sujetopredicado no sólo es contestado desde el mero recurso "técnico" de la imposibilidad de reducir a él las relaciones asimétricas (las auténticamente "externas"), como se piensa a menudo. La teoría relacional del juicio sienta las bases del atomismo lógico de forma tan directa que son los términos y sus relaciones en conjunto los que minan cualquier posibilidad metafisica de fundamentar el concepto de sustancia. Por eso los frecuentes intentos que se han hecho de reducir toda la teoría russelliana de las relaciones al recurso citado no pasan de constituir la deformación profesional, tan frecuente hoy día, de quienes, dominando ciertas técnicas formales, atribuyen su manejo, como recurso exclusivo, a quienes en el pasado también disponían de otros recursos, tal vez menos presentables ahora. ${ }^{33}$

\section{Movimiento, pluralidad y espacio}

Para Russell, desde un punto de vista físico, si se hace descansar la fuerza en sus efectos, no escapamos de la relatividad (Russell pretendía defender a

favor de sus verdaderos constituyentes: los términos y sus relaciones. Por lo mismo, no hay que olvidar el importante papel de Bradley en el origen de la teoría referencialista del significado como entidad existente en términos de "forma lógica" por encima de la forma gramatical.

33 Ishiguro (1972a, 73 ss. y 101 ss.) ha negado que Leibniz tuviese la pretensión de reducir las relaciones a propiedades, argumentando que, en todo caso, hay que valorar su intento de forma técnica, o sea, sin pretensiones metafísicas, al estilo de un desafío. Royse 1980a ha mostrado las posibilidades técnicas de la reducción de relaciones a propiedades utilizando el enfoque de Wiener-Kuratowsky y la teoría de los tipos. Pero, aunque Russell llegase a deformar a Leibniz aquí, lo importante es constatar el instrumental del que se servia, que no era otro que la teoría de las relaciones que acababa de desarrollar en los manuscritos. Körner 1979a ha insistido en el hecho de que, en última instancia, lo que hace Russell ante la idea de oponer su propia lógica a la de Leibniz; aduce para ello la indiferencia de Russell ante la idea de Wiener de reducir las relaciones a clases. Pero esa indiferencia, o rechazo, puede explicarse mejor, creo yo, porque de ser aceptada como auténtica reducción destruiría una gran parte del trabajo de Principia (similarmente a lo que sucedió con la idea del functor de incompatibilidad de Scheffer). (Sobre la reacción de Russell a Wiener véase Grattan-Güinness 1975a.) En todo caso la polémica sobre si Russell entendió o no la teoría de las relaciones de Leibniz continúa: para Rescher 1979a (p. 59 ss.) la postura de Russell es confusión pura y para Glouberman 1979a es necesario reconstruir a fondo la propia postura de Leibniz, lo que, según él, ninguno de los comentaristas había logrado hasta ahora. 
Newton contra Leibniz), ya que el efecto sólo puede medirse, a su vez, por el movimiento mismo (PL, 86). Pero, además, el movimiento absoluto no es compatible con la propia teoría relacional del espacio de Leibniz, sobre todo teniendo en cuenta que Newton había derivado la posición absoluta con argumentos parecidos. Ni tampoco con su teoría de las mónadas, pues, si consideramos dos de ellas y la fuerza reside en una, cuando la otra refleje (o exprese) el movimiento de esta primera, se estará presuponiendo cierta interacción. Salvo que situemos la fuerza en las dos, en cuyo caso la noción no servirá para discriminarlas, como se había supuesto. Russell concluye en la imposibilidad de deducir la fuerza como medio de escapar a la relatividad del movimiento. $\mathrm{Y}$ ve en ello el resultado de la negativa de Leibniz a considerar el movimiento como una relación externa cuya naturaleza no puede verse influida: "EI movimiento, en su propia naturaleza, o es o no es relativo, y la introducción de la fuerza no puede establecer ninguna diferencia en esa naturaleza" (PL, 87).

El mismo resultado se alcanza si se examina la cuestión desde el punto de vista metafísico (PL, $§ 42$ ). Aquí, añade Russell, Leibniz considera que la base de la fuerza es la misma que la de la actividad en general. Pues sólo la fuerza puede suplir de realidad al movimiento. Pero ello supone convertir una relación entre momentos y entre cuerpos en diferentes lugares (el movimiento) en una cualidad (fuerza), to que vulnera la nueva lógica de Russell (PL, 88).

En cuanto a la pluralidad, el problema es muy simple: se trata de hacer compatibles la teoría de que el universo está constituido de mónadas con el hecho aparente de su unidad como un todo. Según Leibniz, aquí se halla involucrada la comparación entre lo ideal (la continuidad, el infinito) y lo actual (la sustancia), es decir, la divisibilidad de lo posible y la de lo actual (PL, 111). Para Russell el problema sólo puede plantearse partiendo de la indistinción entre análisis lógico y análisis ontológico, la teoría relacional, y la irreductibilidad de los juicios de pluralidad al esquema sujeto-predicado. Leibniz resolvió el problema negando que la noción de totalidad fuese aplicable a los agregados (como sucede en el mundo empírico) sobre la base de que lo único real son los constituyentes y la unidad es mero ens rationis (PL, §63). Con ello podía negar el numero infinito a pesar de admitir el infinito actual en general; por tanto la aparente unidad y continuidad del mundo es imposición nuestra.

Según Russell se trata aquí de una "legítima deducción" de la teoría de que todas las proposiciones participan del modelo sujeto-predicado y, como el juicio que afirmaría la existencia de una pluralidad de sustancias no asigna predicado alguno, Leibniz ha de recurrir a la unidad mental (PL, 116):

La mente y sólo la mente sintetiza la diversidad de las mónadas; cada mónada separada es real aparte de la percepción de ella, pero una colección como tal ad- 
quiere sólo una realidad precaria y derivada de la percepción simultánea. Así la verdad en el juicio de pluralidad se reduce a un juicio con respecto al estado de cada mónada que percibe la pluralidad.

Aquí Russell acusa a Leibniz de caer en el esquema de la predicación, pero su propia teoría difícilmente consigue eludir tal esquema, al atribuir varios sujetos lógicos a la proposición (véase mi 199la, cap. 5) Pues, así, ¿quién o qué los une entre sí? La relación sintética de carácter externo que se necesita para ello se parece, peligrosamente, a la Realided de Bradley, de la que es heredera. Tales átomos lógicos necesitan un "espacio metafísico" absoluto, similar al de Newton en el caso de la física (lo veremos más abajo) y muy parecido al de Wittgenstein en el caso de la lógica del Tractatus, cuyo atomismo lógico deriva directamente de Moore y Russell (véase mi 1990c). (Existe un paralelismo interesante entre la concepción del infinito ( $\mathrm{y}$ sus problemas) de Leibniz y la del propio Russell, a la que me he referido ya en mis 1988a y 1991. Lo más llamativo de esa coincidencia sería, sin duda, la negativa a admitir los transfinitos de Cantor.) $)^{34}$

En lo que se refiere al espacio, en PL se defiende abiertamente el espacio absoluto (como acabamos de ver) contra la teoría relacional, atribuida a Leibniz sobre la base de que toda geometría la requiere "metafísicamente" (PL, 86). En cambio, Leibniz no admitía ni los puntos ni el vacío, considerando que la relación de distancia bastaba para construir el espacio (PL, 92). ${ }^{35} \mathrm{~A}$ partir de ahí el espacio pasa a ser, para Leibniz, algo ideal, como el tiempo (y como toda relación), sin que tenga sentido buscar, en él, partes. Por ello Leibniz no puede admitir puntos e instantes. La relación de distancia es analizada en predicados de los términos relacionados por ella, pero tales términos

34 Grattan-Guinness 1980 c (p. 61) ha querido ver la frase de PL (p. 117 nota) referente a los caminos para escapar a la antinomia del número infinito como un añadido de Russell posterior al Congreso, argumentando que allí fue donde Russell se familiarizó con Cantor. Es una consecuencia más de la costumbre de atribuir al Congreso casi todo lo interesante de Russell. En mi 1988a he mostrado al detalle que precisamente anates del Congreso ya Russell buscaba caminos para escapar de la antinomia, mientras que la aceptación de Cantor supuso la desaparición de tal antinomia, que desde luego no es la famosa descubierta después (véase también mi 1991a, cap. 4). Grattan-Guinness argumenta que la frase no aparece en el manuscrito original de la obra. Sin embargo, por la publicación de las fechas atribuidas por el impresor a las pruebas de los diversos capítulos (en O'Briant, 116-17) sabemos ahora que el capítulo IX estaba listo antes de julio, fecha del Congreso. Según tales fechas, sólo los apéndices y el prefacio fueron posteriores al Congreso. Un indicio más en apoyo de mi postura está en que la única nota que inequívocamente hace referencia a Peano está en la p. 299, después de los apéndices, a pesar de referirse al epígrafe 105, mientras que la susodicha nota se refería al 64.

35 En 1903 b (p. 190) Russell describe su anterior postura como similar a la de Leibniz: "When I formerly held this theory I made abroost weactly the same ettempts to base Geometry on distance; and if the. relational theory were true, such a basis would be alone correct". 
son partes "matemáticas", es decir, meros puntos de vista de las mónadas (PL, 114).

Una vez más Russell se sirve de su nueva lógica: Leibniz parte del rechazo del espacio como algo dotado de un ser absoluto mientras, por otro lado, defiende la noción de sustancia. Pero, para Russell, esta última presupone el esquema sujeto-predicado (lo veíamos más arriba); por ello, si partiendo de ella se dotara al espacio de una existencia en $\mathfrak{s}$, habría que admitir la existencia de una relación absoluta entre ambos, que tendría, necesariamente, el carácter de relación externa: ${ }^{36}$

Pero esta relación será sui generis; no será una relación de sujeto y predicado, pues cada término de la relación existe y puede continuar exisriendo aunque la relación cambie. Ni la cosa ni la parte del espacio resulta aniquilada cuando la parte queda desocupada por la cosa y es reocupada por una cosa diferente. Entonces, la relación entre un lugar y la sustancia que lo ocupa es de tal manera que para ella la lógica tradicional no tiene sitio.

Sobre este tipo de relación sui generis ha de constatarse que Russell disponía ya en sus manuscritos de 1898-1900 de dos clasificaciones diferentes de las relaciones, donde el esquema sujeto-predicado figura sólo como caso particular (de una de ellas) junto a otras relaciones, todas como resultado de las combinaciones posibles entre las propiedades transitiva y simétrica. Sin embargo, Russell no se decidió por una clasificación concreta hasta 1903a; por eso aquí no se sirve de ninguna de ellas.

Esto no impide la preciosa conclusión de Russell en consonancia con su destrucción (mooreana) de la sustancia en favor de los átomos lógicos: "para una filosofia de la sustancia es esencial refutar la realidad del espacio" (PL, 119). El detalle concreto de si se cataloga al espacio de atributo (monismo) o de conjunto de relaciones (monadismo) no afecta a este resultado: para Russell ambos dependen del esquema predicativo.

$36 \mathrm{PL}, 118-19$, Ishiguro 1972a (p. 110) ha negado, aludiendo a este mismo pasaje, que la relatividad del espacio fuese inferida por Leibniz del esquema sujeto-predicado. Argumenta que, como su noción de individuo incluiria todas las cambiantes relaciones que fuera asumiendo durante su existencia, entonces, si toda posición espacio-temporal fuera un individuo de por sí, tendría también que incluir todas sur relaciones; lo cual es imposible "because spatio-tomporal points bape no discermible features of their own, are only 'entia rationis' whose identity depends entircly on the relative position of things". Pero Russell dice sólo que el esquema sujeto-predicado está presupuesto en la teoría de Leibniz, con lo que deja abierta la puerta a una utilización más o menos inconsciente por parte de Leibniz. Además, Russell no pretendía que con su teoría absoluta del espacio las posiciones pasaran a ser sustancias individuales (aunque esto nunca estuvo claro), sino sólo explicar por qué para Leibniz las posiciones absolutas son inaceptables, lo cual parece depender de la hipótesis del esquema sujeto-predicado. De nuevo para nosotros lo importante es ver cómo Russell impone su filosofía. 
En todo caso Leibniz no puede escapar, según Russell, a la evidencia de que hay sólo un espacio y de que éste es previo al espacio fenoménico de cada mónada. La conexión con el tema de la sustancia, que Russell achaca a todo monadismo, es que, al admitirla, debe negarse la realidad del espacio (PL, 130). Pero, para obtener la pluralidad de sustancias coexistentes (las mónadas) debe, subrepticiamente, admitirse aquella realidad. Así, tanto Spinoza como Leibniz basaron sus sistemas en la noción de sustancia; lo que hace falta, según Russell, es fundamentar la metafísica en una noción diferente (PL, 126). En m 1900, y en el trabajo presentado al Congreso (que veremos más abajo) Russell avanzó ya bastante en ese camino. ${ }^{37}$

\section{El método}

Desgraciadamente, la identificación russelliana de lo analítico con lo tautológico (y con lo idéntico) no le permitió valorar la importancia de la lógica de Leibniz para el (futuro) proyecto logicista. En este punto sí que tuvo que esperar al Congreso para convencerse de que sólo la lógica como cálculo podía aportar los auténticos "indefinibles" que andaba buscando. Pero, al no ser capaz de romper su noción de síntesis a priori, procedente de Kant, el estudio de Leibniz no hizo sino agudizar la separación entre lo matemático y lo filosófico, latente ya desde 1897a. Aquí su concepción mooreana de la lógica, aunque le había permitido avanzar, por medio de las relaciones externas, en la filosofía de la matemática, no obstante se reveló incapaz de aliarse eficazmente con la lógica tal y como la defendía, por ejemplo, Couturat. $\mathrm{Al}$ mismo tiempo, aunque la reducción a indefinibles e indemostrables seguía siendo lo esencial de su método, con lo que ello conlleva de importancia para la identificación (también mooreana) entre el análisis lógico-ontológico y la definición, no obstante Russell todavía desconfia de que el intento logicista pueda servir en filosofia de la matemática.

Más bien considera aún la lógica simbólica como "una rama de la matemática", como escribe en el epígrafe 105 de PL (dedicado a la Characteristica Universalis, al que pertenecen también las citas siguientes) y aunque reconoce el valor del "Álgebra universal" de Whitehead como marco global que abarca la lógica formal, el álgebra ordinaria y la geometría "como casos especiales", no pasa de considerarla una idea "matemática". Necesitaba urgentemente que alguien le hiciera ver cómo la lógica de Moore y el esquema logicista podían

37 Russell sitúa el dilema ahora entre el espacio como realidad mental en el Ego y como multiplicidad a la que accedemos mediante la percepción. Como ya estableció al presentar los postulados, Russell achaca el problema (PL, 117) a la combinación de tra premisas inconsistentes por sus consecuencias (y no a dos como pretende Vuillemin 1968a, 169): el esquema sujeto-predicado (la la.); el Ego como sujeto lógico último (la 4a.) y la percepción como conocimiento de un mundo externo (la 5a.). 
reducirse a uno solo: fue la tarea de Peano y su escuela. Mientras tanto, la Characteristica Universalis de Leibniz había de rechazarse, puesto que

aunque en matemática fue una idea de la más alta importancia, mostró en filosofía una incomprensión (misconception) radical, animada por el silogismo, y basada en la creencia en la naturaleza analítica de las verdades necesarias.

Pero las proposiciones analíticas tienen el "defecto formalista" de conducir, según Russell, al método geométrico, como en Spinoza. Con ello lo que quiere significar es, sin duda, que los métodos deductivos son insuficientes: no pueden crear su objeto a pesar de la coherencia. La oposición de Russell ahora es, en el fondo, la oposición posterior al método de la definición "por postulados", es decir, al método axiomático, tal y como se opondría a él en 1903a, y, en parte, lo había hecho ya en su polémica sobre la naturaleza de los axiomas de la geometría (véase mi 1990a). En todo ello faltaba lo más importante, el único requisito capaz de garantizar la autenticidad ontológica de los objetos manejados; es decir, la intuición de los simples: "la tarea de la filosofía es justamente el desculrimiento de aquellas nociones simples y de aquellos axiomas primitivos sobre los cuales debe basarse cualquier cálculo o ciencia" (la cursiva es mía).

Ése era el método que, como hemos visto hasta la saciedad, el propio Russell estaba ya utilizando en los manuscritos pre-París, a pesar del problema que tantas veces se le presentaba acerca de cómo distinguir, sin criterios extramatemáticos, el auténtico "orden lógico"; es decir, el problema de la dificultad de hallar un criterio aceptable para distinguir la intuición "verdadera" de la aparente. Problema que, a su vez, hunde sus raíces en la falta de perspicacia de Russell para darse cuenta de la necesidad de otro criterio ulterior que permitiera asociar los "significados verdaderos" a algo reconocible con facilidad. Algo similar a lo que por entonces se hallaba haciendo Moore con su utilización del lenguaje ordinario como signo de lo auténticamente significado, sólo que con la dificultad adicional de su aplicabilidad a un marco donde, como en la matemática, el profesional está acostumbrado a crear entidades a través de las definiciones. Es, en suma, el problema de compaginar la precisión con el lenguaje ordinario y la pérdida de intuitividad que la primera exige necesariamente

De momento, sin embargo, Russell disponía sólo de la intuición a secas como verdadero método filosofico que se hallaba edificado, a su vez, sobre el rechazo de lo idéntico, es decir, de lo tautológico:

La creencia en que los axiomas primitivos son idénticos conduce a un énfasis en los resultados más bien que en las premisas, lo que se opone radicalmente al verdadero método filosófico. No puede haber ni dificultad ni interés en las premisas si ésras son del tipo " $A$ es $A$ " o " $A B$ no es no- $A$ ". Y así Leibniz supuso 
que el gran requisito era un método adecuado de deducción. Mientras que, de hecho, los problemas de la filosofia serían anteriores a la deducción. Una idea que puede definirse, o una proposición que puede probarse, es algo que tiene sólo un interés filosófico subordinado. El énfasis debería ponerse en lo indefinible y lo indemostrable y aquí ningún método es válido salvo la intuición.

Desafortunadamente Russell no explica (no puede, en realidad) qué quiere decir con "intuición". No obstante, en un prefacio posteriormente desechado escribió: ${ }^{38}$

Pero donde la definición y la prueba son inaplicables, estamos abandonados a ba intuición, a algo que, aunque presupuesto en todas las pruebas y definiciones, en sí mismo sólo puede obtenerse mediante lo que puede llamarse imaginación. Y así la filosofía -aunque debemos, si hemos de creer alguna proposición cualquiera, suponerla capaz de alcanzar alguna verdad— se parece más, en su método, a la poesía que a la ciencia. Depende más bien del genio individual que de la lenta acumulación de trabajo paciente.

Paradójicamente el método auténtico se presenta aquí como la antítesis de las construcciones lógicas del futuro, ahora meras posibilidades matemáticas útiles. Como ya había adelantado Couturat en el prefacio a su 1896a, es la lógica la que debe imaginar posibilidades y, aunque Russell de momento no admite ese papel para la lógica, no podemos olvidar que: (i) el prefacio comentado fue rechazado dando paso a otro donde se habla de la "reconstrucción" lógica de Leibniz, y (ii) Russell siguió siempre defendiendo la intuición como guía de la filosofía y de la lógica. En mi 199la (cap. 5) he explicado como en 1903a se le hace cada vez más difícil defenderse del "formalismo", levantando sin descanso la bandera del acceso "directo" (el antecedente de la acquaintance de 1905). ${ }^{39}$

\section{El trabajo presentado al Congreso y la asimilación de Moore}

Russell presentó al Congreso de París de 1900 un trabajo titulado "Lidée d'ordre et la position absolue dans l'espace et le temps" (1900b). Por su contenido no añade prácticamente nada a lo expuesto (y presupuesto) en PL. En pocas palabras, no es más que la reivindicación de la teoría absolutista del espacio a la que conducía su nueva filosofia de las relaciones externas y la noción

38 Publicado ahora en O'Briant 1979a, pp. 175-76. Sin duda Russell escribió un nuevo prefacio en parte por los “excesos” cometidos en éste al conectar la intuición con la imaginación.

39 En la recensión a 1896 a de Couturat rechaza su método de las construcciones lógicas como mera "rendición" a la facilidad. Sobre todo ello cabe destacar el paralelismo que, no obstante las críticas, existe con Leibniz en el tema de los simples, la definición como análisis y el acceso intuitivo a todo ello; véase Martin 1960a (pp. 35-36 y 41) al respecto. 
de orden. Y ello con el consiguiente ataque a la teoría relacional del espacio de Leibniz (y Lotze), que había sido la suya propia (en 1897a). El artículo presenta, no obstante, una característica interesante: la de servirse de forma tan sistemática de la filosofía de Moore que puede tomarse, sin exageración, como verdadero compendio de ésta. ${ }^{40}$ Divido el comentario en cuatro partes principales.

(i) La posición de Russell es muy clara: si se admite la realidad de los sucesos y de las cosas en el espacio, tanto éste como el tiempo son reales (1900b, 241). Era tanto como decir que la realidad de los términos y las relaciones originan la realidad del espacio "metafísico" donde éstos se hallan, como exigía la nueva lógica. La disputa se resume así: partiendo de una serie de términos que tienen posiciones, ${ }^{41}$ "puede dudarse de si las posiciones nacen de relaciones mutuas entre los términos o si son términos nuevos con los cuales los términos originales mantienen relaciones de cierto tipo". Naturalmente Russell escoge la segunda postura. Lo que en la nueva lógica significaba, sencillamente, convertir las propiedades en un nuevo término y las relaciones correspondientes (como en los manuscritos y PL).

(ii) La refutación de la teoría relacionista es presentada como un proceso formal en el caso del tiempo. La teoría sostiene la inexistencia de los momentos, reduciéndolo todo a la relación de simultaneidad entre sucesos. En contra, la teoría "absolutista" mantiene la existencia de una relación entre cada suceso y el momento en que éste tiene lugar (de manera parecida se trató en los manuscritos previos la igualdad en relación con la cantidad). Se ofrecen dos argumentos: el primero niega la posibilidad, necesaria a la teoría relacionista, de obtener los sucesos mediante relaciones mutuas entre cualidades. Sobre la base de que la tal teoría, al negar la existencia de tiempos diferentes, no puede usar éstos como base para transformar las cualidades en sucesos. Pero, como es necesario establecer relaciones temporales entre las mismas cualidades, como se ve cuando decimos que el dolor (como tal) precede al placer (como tal), entonces no podremos pasar nunca de las cualidades a los sucesos.

El segundo argumento concluye su exposición en un resumen formal (1900b, 247s.): si los términos con posición se desean disponer siguiendo la teoría relativista, es preciso que entre cada par de ellos se dé, o bien la si-

40 Afortunadamente, y a diferencia de PL, aquí sí que se citan directamente los trabajos publicados de Moore (en concreto 1899 a y 1900 b). Hubiera sido un verdadero escándalo el continuar asumiendo aquella filosofia como original refugiándose en un vago reconocimiento, máxime en un congreso internacional.

41 Russell desarrolla todo el tema a través del concepto de serie, manejando la distinción entre aquellas que son posiciones (enteros, cantidades o instantes) y las que tienen posiciones (colecciones, magnitudes y sucesos). Además, utiliza cierto aparato formal para la clasificación de las relaciones basado en las propiedades transitiva y simétrica, esto último como en los manuscritos, incluyendo también algunos signos tomados de Schröder (como R). 
multaneidad (S) o bien la prioridad (R) o bien la posterioridad $(\breve{R})$. Pero las cualidades no pueden satisfacer esta condición y los sucesos no difieren de ellas más que en tener posición temporal única. Por tanto hay que admitir las posiciones temporales como nuevos términos en relación con los cuales las cualidades se transformen en sucesos (si se quiere evitar un círculo vicioso).

(iii) La aplicación de lo anterior al espacio tiene dificultades especiales pero, según Russell, aunque no existe un argumento tan simple que pruebe la existencia de la posición absoluta, es posible mostrar que las dificultades de la teoría relativista son aun mayores. Dicha teoría mantiene que el espacio está constituido sólo por relaciones cuyos términos no son espaciales, sino puntos materiales. Para Russell, su popularidad se basa en que habitualmente no se extraen de forma consistente todas sus consecuencias. Cuando esto se lleva a cabo, se ve que la única relación que admite entre los puntos (la distancia) es un "concepto complejo" que puede analizarse en dos elementos: la distancia como magnitud y la dirección (o recta proyectiva), ${ }^{42}$ con lo que la teoría no cumple su objetivo de prescindir de rectas y planos como entes imposibles de identificar.

(iv) La parte más interesante es la última, donde se lleva a cabo toda una demostración de la aplicabilidad de la nueva filosofía. La destrucción de los argumentos contra la teoría absolutista tiene lugar según el consabido modelo de PL: reduciendo cada uno de ellos a uno de los típicos errores contrarios a la teoría relacional del juicio. Así, las relaciones no son sólo representaciones en una conciencia que las crea $(1900 \mathrm{~b}, 259)$. Tales representaciones serían creencias en proposiciones que afirmen las relaciones y, si tales relaciones no tienen más ser que el de esas creencias, entonces las creencias son falsas. Tampoco son estados internos de los elementos relacionados. Si así fuera se estaría presuponiendo la existencia de objetos diversos, en cuyo caso sus diferencias no podrían reducirse a estados internos: primero habría que distinguirlos (antes de hacer lo propio con sus estados; este argumento es similar al usado en PL con el tema de la sustancia y sus predicados).

El modelo sujeto-predicado tiene consecuencias inaceptables (1900b, 26263): (a) no tiene en cuenta la mayor parte de las proposiciones y analiza falsamente el resto; (b) lleva a la contradicción, ya que la proposición que establece la existencia de predicados no se atiene al esquema; (c) implica la diversidad, aunque sólo sea la existente entre sujeto y predicado, y, por último, (d) es una relación que no modifica la naturaleza de sus términos, lo que equivaldría a tener otro predicado, con el consiguiente regreso al infinito. ${ }^{43}$ Por último, el esquema conduce a otro error popular: la identidad de los

42 1900b, 251. Aquí Russell retoma algo de lo establecido en sus respuestas a Coururat y Poincaré; véase la sec. 2 , arriba.

43 Aquí la referencia a Moore es directa: :Lidhe qu'un terme peut etre susceptible de modifica- 
indiscernibles, que se manifiesta también en la teoría según la cual todos los puntos son exactamente similares, lo que puede significar sólo que carecen de predicados diferentes.

Pero "cuando se ha reconocido que no hay distinción fundamental entre sujetos y predicados, se ve que dos términos simples cualesquiera deben diferir de manera inmediata; hay dos y esto constituye la totalidad de sus diferencias" (1900b, 269-70). Esto último remarca a la perfección cómo la teoría absolutista conduce directamente al predominio de la diferencia numérica, tal como lo había establecido Moore. Sin embargo, Russell tiene el indudable mérito de explicar (y aplicar) con más claridad y eficacia la propia filosofía de Moore (como le sucedió otras veces al aplicar métodos ajenos).

También se repite la negación de las diversas especies de ser: hay sólo el ser y la existencia (y ambos pertenecen al espacio vacío, contra los representantes de la teoría relativista). De ellos Russell ofrece las definiciones mooreanas habituales (aunque ahora sin citar a Moore) según las cuales el ser es lo que pertenece a todo término concebible, es decir, a todo lo que puede entrar en una proposición, y la existencia es la propiedad de algunos seres de estar en determinada relación con el concepto de existencia. En consecuencia la teoría existencial del juicio, que afirma que toda proposición trata de algo existente, cae por su base y se contradice, ya que al considerar la existencia misma admitimos ya proposiciones no existenciales.

Por último, una nueva "discusión lógica” deshace otro error: el que pretende probar la aprioridad del espacio, en sentido kantiano, sobre la base de que hay proposiciones necesarias sobre su naturaleza. Ahora aplica Russell la teoría mooreana de la necesidad (que cita). De acuerdo con ella, lo que nos parece imposible pensar o creer resulta ser sólo algo más bien psicológico que lógico. Esto último no es más que "un simple hecho", de acuerdo con el cual "lo que es verdadero es verdadero y lo que es falso es falso y no hay nada más que decir" (1900b, 274-5). La postura de Moore sobre la necesidad se aplica literalmente: las proposiciones de las que no podemos dudar son las que implican un gran número de otras proposiciones que creemos verdaderas (sin embargo, en m 1902? se atacaría esta postura). El artículo termina remarcando el hecho de que a las ventajas de la teoría absolutista sólo puede oponerse "una lógica antigua" (1900b, 277) fácilmente refutable.

A modo de conclusión quisiera sentar algunos puntos brevemente. Ante todo el hecho evidente de que la influencia de Moore se halla ya consolidada antes del Congreso, con sus ventajas e inconvenientes. Como hemos visto, se hallan presentes la práctica totalidad de sus tesis. En consecuencia, los reconocimientos explícitos en 1903a y en 1904a son tardíos e incompletos (ya 
que citan tesis demasiado concretas). Cabe reconocer, pues, que lo que más tarde se llamó "atomismo lógico" está ya presente (como consecuencia de la teoría del juicio mooreana) antes del logicismo pleno de Russell, a pesar de no contarse todavía con las técnicas formales características. Russell lo admite cuando no sitúa el hecho en 1900, sino en 1899 (núcleo de la influencia de Moore y fecha de su 1899a): "Hay una división mayor en mi obra filosófica: en los años 1899-1900 adopté la filosofía del atomismo lógico y la técnica de Peano en lógica matemática" (1959a, 9).

En segundo lugar, aunque atomismo lógico y lógica matemática son cosas muy distintas, no obstante el primero posibilitó la búsqueda implícita y la aceptación abierta de la segunda. El platonismo de Moore, la importancia de las relaciones (es decir, el pluralismo, que se adaptaba tan bien a la matemática) y, sobre todo, el énfasis en lo indefinible como material de construcción, lo hicieron posible. Como he mostrado en mi 1988a, el progreso en la fundamentación de la matemática fue real y efectivo a pesar del desprecio posterior del propio Russell hacia los manuscritos.

Por último, aunque es cierto que Moore enseñó a Russell que el método fundamental de toda filosofía es la definición, no obstante no le aportó técnicas concretas para aplicar tan magro programa a un campo tan difícil como la fundamentación de la matemática (lo que sólo llegaría con Peano y la admisión de Cantor). La insuficiencia del método de Moore radicaba en que, aunque permitía sentar las bases para el atomismo lógico imprescindible y, por tanto, para la "teoría de conjuntos" tal como la entendió Russell al principio (al incidir sobre todo en la sintesis entre los términos del juicio), sin embargo favorecía un tipo de lógica basada en el todo/parte (es decir, en la inclusión). Y, aunque Russell conocía otros avances lógicos (la línea Boole-Whitehead), no llegó a interesarse a fondo por sus logros (véanse mis 1988c y 1991a, cap. 4), ni siquiera por la interpretación proposicional, después la base de su lógica, quizá por no disponer de una teoría satisfactoria de la implicación lógica. En todo caso, la distinción peaniana entre pertenencia e inclusión fue el principio de la integración de la nueva filosofía en la verdadera "nueva lógica": la de Peano.

\section{BIBLIOGRAFIA}

Bergmann, G. 1956a: "Russell's examination of Leibniz examined", Phil. Sci. 23: 175-203.

Carmo, C. H. 1972a: "Revisao critica da obra de Bertrand Russell sobre Leibniz", Rev. Port. Fil. 28: 421-457.

Clark, R. W. 1975a: The life of Bertrand Russell, Penguin, Londres, 1978. 
Couturat, L. 1986a: De l'infini matematique, Alcan, París.

- 1898a: Recensión de B. Russell 1897a, Rep. Met. Mor 6: 354-358.

— 1898b: "Sur les rapports du nombre et de la grandeur", Rev. Met. Mor 6: 422447.

- 1902a: "Sur la métaphysique de Leibniz", Rer, Met. Mor 10: 1-25.

Glouberman, M. 1979a: "Leibniz and relationality", Critica 11: 29-50.

Grattan-Guinness, I. 1975a: "Wiener on the logics of Russell and Schröder", Ann. Sci 32: 103-132.

— 1980c: "Georg cantor's influence on Bertrand Russell", Hist. Phil. Log. 1: 6193.

Hertz, H. 1894a: Principles of mechanics 1956, Dover, Nueva York.

Griffin, N. 1988a: "The Tiergarten programme", Russell 8: 19-34.

— 1990a: Russell's idealist apprenticeship, Oxford Univ. Press, en prensa.

Hilbert, D. 1899a: Fundamentos de la geometria, CSIC, 1953, Madrid.

Ishiguro, H. 1972a: Leibniz's Pbilosophy of Logic and Language, Duckworth, Londres. Körner, S. 1979a: "On Russell's Critique of Leibniz's Philosophy". En Roberts 1979a, 171-181.

Martin, R. M. 1960a: Leibniz. Logique et metaphysique, Beauchesne, 1966, París. Moore, G. 1899a: "The Nature of Judgement", Mind 8: 176-193.

_ 1900a: "Identity", Proc. Arist. Soc. 1: 103-127.

- 1900b: "Necessity", Mind 9:288-304.

O'Briant, W. H. 1979a: "Russell on Leibniz", Studia leibnitiana 11/2: 159-22.

Parkinson, G. H. R. 1965a: Logic and Reality in Leibniz's Metaphysics, Clarendon, Oxford.

Rescher, N. 1979a: Leibniz. An Introduction to bis Philosophy, N. J. Rowman, Totowa. Roberts, G. W. 1979a: (ed.) Bertrand Russell Memorial Volume, Allen \& Unwin, Londres.

Rodríguez-Consuegra, F. A. 1987a: El metodo en la filosofia de Bertrand Russell. Un estudio sobre los origenes de la filosofía analitica a través de la obra de Russell, sus manuscritos ineditos $y$ los autores que más le influyeron. Tesis doctoral, Universidad de Barcelona, $x+800$ pp.

_ 1987b: "Bibliografia de Bertrand Russell en español", Mathesis 3: 183-197.

—_ 1987c: "Russell's Logicist Definitions of Numbers 1899-1913: Chronology and Significance", Hist. Fil. Log 8: 141-69.

— 1988a: "Bertrand Russell 1898-1900: una filosofia de la matemárica inédita", Mathesis 4: 3-76.

_ 1988b: "Elementos logicistas en la obra de Peano y su escuela", Mathesis 4: 221-299.

_- 1988c: "Bertrand Russell 1900-1913: los principios de la matemática, parte 1a.", Mathesis 4: 355-392.

1988d: "Bertrand Russell 1900-1913: los principios de la matemática, parte 2a.", Mathesis 4: 489-521.

— 1989a "Russell's Theory of Types; 1901-1910: its Complex Origins in the Unpublished Manuscripts", Hist. Phi. Log. 10: 131-164.

— 1989b: "The Origins of Russell's Theory of Descriptions According to the Unpublished Manuscripts", Russell 9: 99-132. 
1989c: "La pérdida de certidumbre en la matemática y la ciencia contemporáneas". Aparecerá en Mathesis.

1990a: "Russell's first technical philosophy", Essay-Review of I. Winchester and K. Blakwell (eds.), Antonomies and Paradoxes. Studies in Russell's Early Philosophy, McMaster University Press, Hamilton, 1989 (Russell, 8 (1988) números 1-2). Aparecerá en Hist. Phil. Log. 11/12.

1990b: "Bertrand Russell 1895-1898: una filosofia prelogicista de la geometría", Diálogos, 55: 71-123.

1990c: "El impacto de Wittgenstein sobre Russell: últimos datos y visión global". Sometido a Theoria.

_ 1990d: "El logicismo russelliano: su significado filosófico". Aparecerá en Critica.

1990e: "La primera filosofía de Moore". Aparecerá en Ágora (en dos partes).

1990f: "La influencia de Bradley en los orígenes de la filosofía analítica". Sometido a Er. Revista de Filosofia.

- 1990g: "Some New Light on Russell's Inextricable Tangle' Abour Meaning and Denotation". Aparecerá en Russell.

— 1990h: "A Comparison of the Theories of Descriprions by Frege, Peano and Russell". Sometido a Jm. Philos. Logic.

— 1990i: "Bertrand Russell 1929-1948: una filosofía de la ciencia entre el holismo y el atomismo". Aparecerá en Diálogos.

1990j: "Bertrand Russell and Bradley's Ghost: Evolution and Significance of Russell's View's Concerning Relations". Sometido a Synthese.

- 1991a: Bertrand Russell's Mathematical Philosophy: Origins and Depelopment. Aparecerá en Bibliópolis, Nápoles.

- 1991b: "A Global Viewpoit on Russell's Philosophy". Ensayo-reseña de Wade Savage y Antony Anderson, 1989a. De próxima publicación en Diálogos, 56.

- 1992a: "Marhematical Logic and Logicism from Peano to Quine", En I. Grattan-Guinnes (ed.), Encyclopaedia of the History and Pbilosophy of the Mathematical Sciences, Routledge, Londres. De próxima publicación.

Royse, J. R. 1980a: "Leibniz and the Reducibility of Relatios to Properties", Studia Leibnitiana 12/2: 178-204.

Russell, B 1897a: An Essay on the Fundations of Geometry, University Press, Cambridge. - 1897c: "On the Relations of Number and Quantity", Mind. 6: 326-341.

— 1897f: "Seems, Madam? Nay, it is", En 1938a: 105-111, m1898: An Analysis of Mathematical Reasoning, manuscrito inédito.

— 1898a: Recensión de A. Love, Theoretical Mechanics, Mind 7: 404-411.

- m1899: The Fundarnental Ideas and Axioms of Mathematics, manuscrito inédito. ml900: Principles of Mathematics, (Draft of 1899-1900), manuscrito inédito.

— 1900a (PL): A Critical Exposition of the Philosoply of Leibniz, Cambridge University Press. Segunda edición, con nuevo prefacio, Allen \& Unwin, Londres, 1937. 1900b: "Lidee de l'ordre et de la position absolue dans l'espace et dans les temps", Actas del Comgres international de philos. log et bist. des sciences, de París, 1900, vol. III, Colin, París, 1901.

— ml902?: "Necessity and Possibility", manuscrito inédiro. 
_ 1902f: "What shall I read?", registro personal de lecturas entre 1891 y 1902, en 1983a: 345-365.

- 1903a: The Principles of Mathematics, Cambridge University Press. 1903b: "Recent Work on the Philosophy of Leibniz", Mind. 12: 177-201. 1904a: "Meinong's Theory of Complexes and Assumptions". En 1973a: 21-76. 1944b: "Reply to Criticisms". En Schipp 1944a: 681-741.

1959a: My Philosophical Development, Unwin Books, 1975, Londres.

1967a: Autobiografia, vol I., Aguilar, Madrid, 1968.

- 1973a: Essays in analysis, D. Lackey (ed.), Allen \& Unwin, Londres. 1983a: Cambridge Essays, 1888-99, vol. I de los Collected Papers, Allen \& Unwin, Londres.

Schilpp, P. 1944a: (ed.) The Philosophy of Bertrand Russell, Open Court, La Salle, Ill., $1971^{4}$.

Serres, M. 1968a: Le systeme de Leibniz et ses modéles mathematiques, P.U.F., París.

Spadoni, C. 1977a: Russell's Rebellion Against Neo-hegelianism. Tesis doctoral inédita, Universidad de Waterloo, Ontario, Canadá.

Vuillemin, J. 1968a: Legns sur la premiere philosophie de Russell, París, Colin.

Wade Savage, C. y Anthony Anderson, C. 1989a: (eds.), Rereading Russell: Essays in Bertrand Russell's Metaphysics and Epistemology, vol. XII de Minnesota Studies in the Philosoply on Science, University of Minnesota Press, Minneapolis, 1989.

Watling, J. 1970a: Bertrand Russell, Oliver, Edimburgo.

Whitehead, A. N. 1898a: A Treatise on Universal Algebra, Cambridge University Press. Wiener, P. P. 1944a: "Method in Russells work on Leibniz". En Schilpp 1944a: 259276.

Wittgenstein, L. 1922a: Tractatus Logico-philosophicus, Alianza, Madrid, 1973. 